\title{
Synthesis of 1,3,4-Thiadiazole Derivatives and Microbiological Activities: A Review
}

\author{
Barbosa, G. A. D.; de Aguiar, A. P.*
}

Rev. Virtual Quim., 2019, 11 (3), 806-848. Data de publicação na Web: 6 de maio de 2019

http://rvq.sbq.org.br

\section{Síntese de Derivados de 1,3,4-Tiadiazol e Atividades Microbiológicas: Uma Revisão}

Resumo: A resistência bacteriana associada a diferentes antibióticos é uma limitação para o tratamento de infecções e isto tem estimulado o desenvolvimento de novos agentes antimicrobianos. Neste aspecto, novos derivados de 1,3,4-tiadiazol-2,5-dissubstituídos, os quais apresentam diversificada atividade biológica, têm sido o foco de vários projetos de pesquisa nos anos recentes. Este artigo destaca as principais metodologias para a síntese deste heterociclo utilizando acilidrazinas, ditiocarbazatos, tiossemicarbazidas, 1,3,4oxadiazóis. Adicionalmente, derivados de 1,3,4-tiadizol-2,5-dissubstituídos com ação antimicrobiana são reportados.

Palavras-chave: Tiadiazol; tiosemicarbazida; bioatividade; antimicrobiano; tiosemicarbazona.

\begin{abstract}
Bacterial resistance associated to different antibiotics is a limitation for the treatment of infections and this has stimulated the development of new antimicrobial agents. In this aspect, novel 2,5- disubstituted-1,3,4-thiadiazole derivatives, which present a diversified biological activity, have been the focus of various research projects in recent the years. This article highlights the main methodologies for the synthesis of this heterocycle using acylhydrazines, dithiocarbazates, thiosemicarbazides, 1,3,4-oxadiazoles. Additionally, 2,5disubstituted-1,3,4-thiadiazole derivatives with antimicrobial action are discussed.
\end{abstract}

Keywords: Thiadiazoles; thiosemicarbazide; bioactivity; antimicrobial; thiosemicarbazone.

\footnotetext{
* Instituto Militar de Engenharia, Seção de Engenharia Química, Praça General Tibúrcio 80, CEP 22290-270, Rio de Janeiro-RJ, Brazil.

Malcino@ime.eb.br

DOI: $10.21577 / 1984-6835.20190058$
} 


\section{Synthesis of 1,3,4-Thiadiazole Derivatives and Microbiological Activities: A Review \\ Gabriela de Andrade Danin Barbosa, Alcino Palermo de Aguiar*}

Instituto Militar de Engenharia, Seção de Engenharia Química, Praça General Tibúrcio 80, CEP 22290-270, Rio de Janeiro-RJ, Brazil.

*alcino@ime.eb.br

Recebido em 19 de setembro de 2018. Aceito para publicação em 4 de março de 2019

\section{Introduction}

2. Methodologies for the Synthesis of 1,3,4-Thiadiazole

2.1. From acylhydrazines

2.2. From dithiocarbazates

2.3. From thiosemicarbazides

2.4. From thiosemicarbazones

2.5. From 1,3,4-oxadiazoles

3. 1,3,4-Thiadiazoles: Microbiological Activities

4. Conclusion

\section{Introduction}

Heterocyclic compounds play an important role in biological processes, especially heterocycles that contain nitrogen, because of their wide use in medicinal scaffolds for active agents. ${ }^{1}$ The 1,3,4-thiadiazole nucleus, which makes up the azole group, is a versatile pharmacophore and exhibits a wide variety of biological activities. In addition to the 1,3,4thiadiazole (1), there are three other isomers: 1,2,3-thiadiazole (2), 1,2,4-thiadiazole (3) and 1,2,5-thiadiazole (4) (Figure 1)..$^{2-6}$<smiles>c1nncs1</smiles>

(1)<smiles>c1csnn1</smiles>

(2)<smiles>c1cnsn1</smiles>

(3)
(4)

Figure 1. Structure of the thiadiazole isomers

The thiadiazole core can be employed as a bioisostere for other heterocycles, for example oxadiazoles. In this case, the substitution of the oxygen atom for sulfur maintained the biological activity and increased the led to the maintenance of 
biological activity and an increase in lipophilicity. ${ }^{7,8}$ Among the different azole heterocycles, 1,3,4-thiadiazoles have aroused much interest as can be seen from the large number of different synthetic methodologies reported in the literature. Furthermore, these compounds have very diversified biological properties, ${ }^{6-15}$ including: antifungal, ${ }^{16}$ antiinflammatory, ${ }^{17}$ antibacterial, ${ }^{18}$ antiparasitic, ${ }^{19}$ antioxidant, $^{20} \quad$ antidepressant, $^{20}$ anticonvulsivant, ${ }^{21}$ diuretic, ${ }^{22}$ and antitumoral agents (Figure 2 ). ${ }^{23}$<smiles>CC(=O)Nc1nnc(S(N)(=O)=O)s1</smiles>

(5)<smiles>Cc1nnc(NS(=O)(=O)c2ccc(N)cc2)s1</smiles>

(6) diuretic<smiles>Cc1c(C)c2ccc(OCc3nnc(C(C)C)s3)cc2oc1=O</smiles>

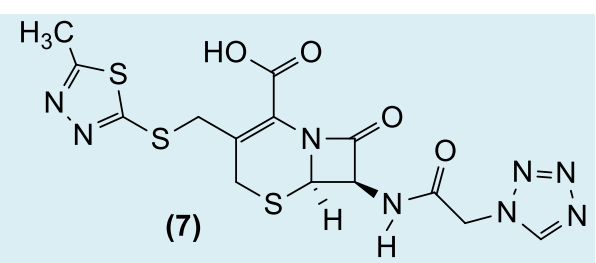

antibacterial

Figure 2. Examples of bioactive compounds containing 1,3,4-thiadiazole

Certain derivatives of this class, such as acetazolamide (5), sulfamethiazole (6), cefazolin (7), atibeprone (8) are already commercialized (Figure 2). ${ }^{3,21,24}$ The drug megazol (9) was considered a possible alternative for the treatment of Chagas's disease, however, it has been shown to be very mutagenic, discouraging the continuity of the research. ${ }^{19,25}$

Currently microbial resistance to drugs is a concern in Medicinal Chemistry, which can be due to gene transfer or excessive drug usage. Over the last few decades there has been an increase in drug resistance and in the detection of hospital-acquired infections caused by multidrug resistant strains and this situation is considered a public health problem. This drug resistance has compromised the treatment of infectious diseases and at the same time has stimulated the search for new bioactive substances. The antibacterial and antifungal properties associated with the thiadiazole nucleus have been widely researched. ${ }^{10,26,27}$ Futhermore various synthetic methodologies to produce thiadiazole derivatives have been reported..$^{26,27}$

This report reviews the evolution of the main syntheses of 1,3,4-thiadiazole derivatives, as well as examples of thiadiazole structure with antimicrobial activity reported over the years.

\section{Methodologies for the Synthesis of 1,3,4-Thiadiazole}

Since the late XIX century different reactions involving 1,3,4-thiadiazoles have been reported in the literature. ${ }^{28-35}$ One of the first authors to report a synthesis of a thiadiazole was Bush in $1894,{ }^{29}$ who reacted hydrazine sulfate and carbon disulfide in the presence of an alcoholic solution of potassium hydroxide. According to Losanitch, ${ }^{29}$ the development of 1,3,4-thiadizole chemistry is linked to the discovery of hydrazines. The treatment of the hydrazine salt of 2,5-dithiol1,3,4-thiadiazole with concentrated 
hydrochloric acid formed the compound $\mathbf{1 2}$. Losanitch adapted this method for the synthesis of the heterocycle 12, which was obtained with a $60 \%$ yield from the treatment of carbon disulfide (11) with hydrazine hydrate (10) in the presence of alcoholic ammonia (Scheme 1). ${ }^{29}$

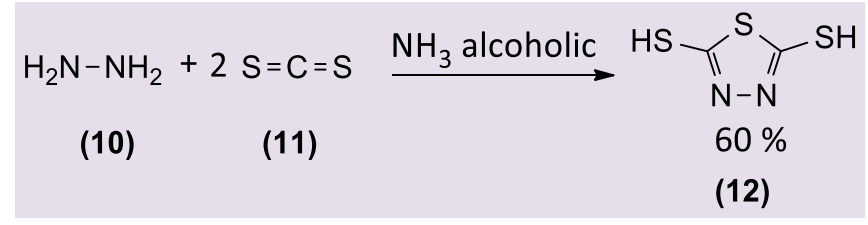

Scheme 1. Synthesis of 2,5-dithiol-1,3,4-thiadiazole

In a subsequent study, Petrow et al. (1958) reported a reaction between thiosemicarbazide (13) and carbon disulfide
(11) which produced compound 14 in a yield ( $81 \%$ ) higher than that of Losanitch (60\%) (Scheme 2). ${ }^{36}$

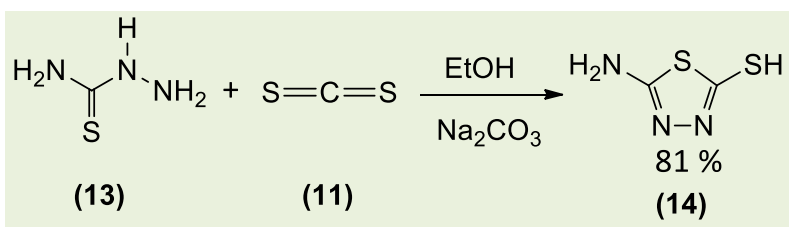

Scheme 2. Synthesis of thiadiazole from thiosemicarbazide and carbon disulfide

Among the different substitution patterns obtained for the 1,3,4-thiadiazole the compounds derived from 2-amino-5substituted-1,3,4-thiadiazoles have been the focus of different publications. ${ }^{37-39}$ Usually, these derivatives are available via basic routes through cyclization of acylhydrazines, dithiocarbazates, thiosemicarbazides, thiosemicarbazones or transformation of 1,3,4-oxadiazoles.

\subsection{From acylhydrazines}

In general, the reactions between acylhydrazide and sulfur reagents $\left(\mathrm{CS}_{2}\right.$, isothiocyanate or dithiocarbamates) for thiadiazoles synthesis consists of two or more steps ${ }^{40-42}$ where the first is to synthesize the relevant thiosemicarbazides or dithiocarbazides which can then be converted into thiadiazoles.

Mirzaei et al. (2008) investigated the synthesis of thiadiazoles from acylhydrazines (Scheme 3). The reaction of acylhydrazine (15) with substituted isothiocynate (16) and sodium hydroxide in ethanol yielded thiosemicarbazide (17a-f) which was cyclized in an acidic medium to provide $\mathrm{N}$-substituted 2-amino-5-[(2-methyl-5-nitro-1H-imidazol-1$\mathrm{yl}$ )methyl]-1,3,4-thiadiazoles (18a-f). ${ }^{40}$ 
Barbosa, G. A. D.; de Aguiar, A. P.

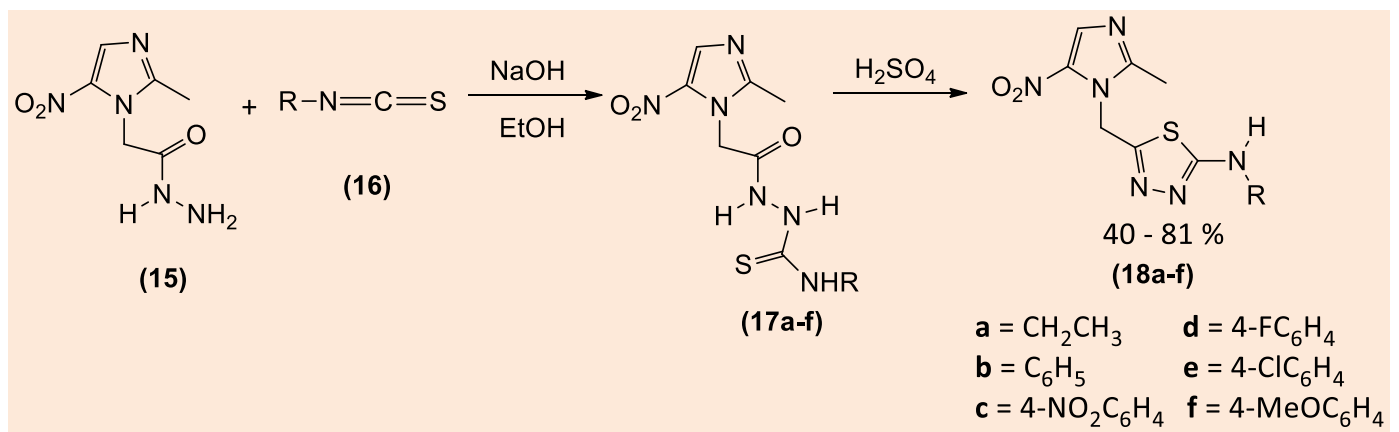

Scheme 3. Synthesis of thiadiazole from acylhydrazine and isothiocynate

Ghate et al. (2017) reported the synthesis of 1,3,4-thiadiazoles from isothiocynate and isoniazid in two steps (Scheme 4). At first the intermediate $\mathbf{2 1}$ was synthesized from 2-
methylsulphonitrile-1[H] benzimidazole (19) and isoniazid (20), which was refluxed with 50 $\% \mathrm{H}_{2} \mathrm{SO}_{4}$ to produce 1,3,4-thiadiazole derivate (22) with a yield of $60 \%{ }^{42}$

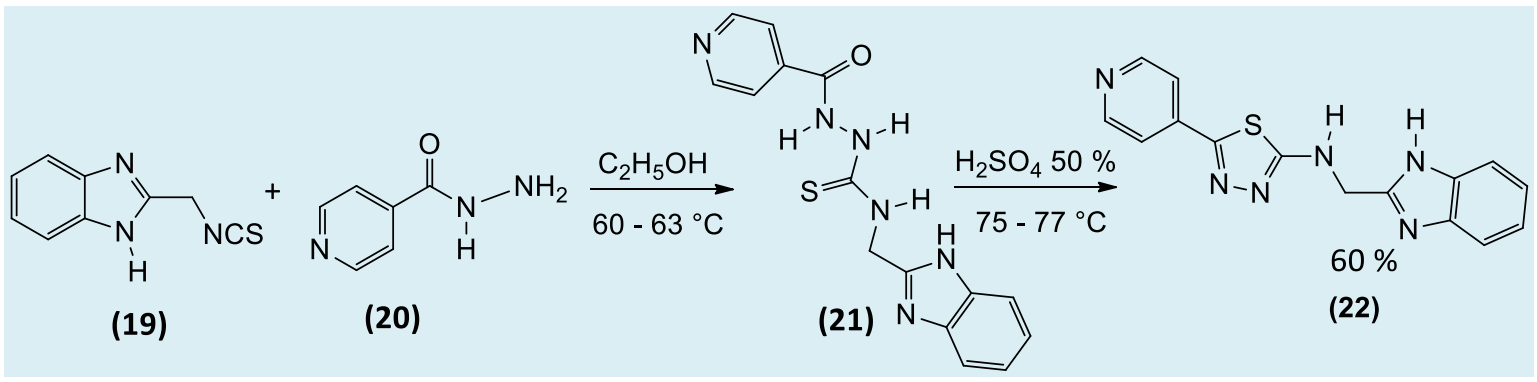

Scheme 4. Synthesis of 1,3,4-thiadiazole from acylhydrazine reported by Ghate et al. (2017)

In 2010, Aryanasab ${ }^{43}$ developed a one-pot synthesis using isothiocyanate (24) and acylhydrazides (23) to furnish 2-substituted1,3,4-thiadiazoles (25) in the presence of water and triethylamine. Under the same conditions the authors used dithiocarbamates (26a-e) and acid hydrazides (27a-e) to produce 28a-e in good yields (51-97 \%) (Scheme 5). ${ }^{43}$<smiles>NNC(=O)Cc1ccccc1</smiles>

(23)

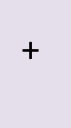<smiles>OCNO</smiles><smiles>S=C=Nc1ccc(I)cc1</smiles>

(24)<smiles>CCN(CC)C(=O)O[Na]</smiles>

(25)<smiles>[R16]NC(=S)S[R]</smiles>

$\mathrm{R}_{1}=\mathrm{n}-\mathrm{Bu} ; \mathrm{PhCH}_{2}$; phenylethyl<smiles>[R]Nc1nnc([R3])s1</smiles>

(28 a-e)

Scheme 5. One-pot synthesis of 1,3,4-thiadiazoles from acylhydrazine and the sulfur reagents 
Another type of one-pot synthesis of 1,3,4thiadiazole derivatives (31) from carboxylic acids (Scheme 6) was developed by Augustine et al. (2010). ${ }^{44}$ According to these authors, propylphosphonic anhydride (T3P) is generally used as a coupling agent and water scavenger with low toxicity and offers several advantages over traditional reagents, such as having broad functional group tolerance, low epimerization tendency and, above all, high yields and purity. So, the main scope of the report was to evaluate the efficiency of propylphosphonic anhydride (T3P) as a reagent in one-pot synthesis. ${ }^{44}$

The 1,3,4-thiadiazole derivatives were synthesized from the mixture of carboxylic acid (29), hydrazide (30) and phosphorus pentasulfide $\left(\mathrm{P}_{2} \mathrm{~S}_{5}\right)$ or Lawesson's reagent in the presence of propylphosphonic anhydride (T3P), which has been demonstrated to be an efficient reagent for the one-pot synthesis. In most cases, the reaction proceeded with high efficiency. ${ }^{44}$<smiles>[R]C(=O)O</smiles>

(29)<smiles>[R]C(=O)NN</smiles>

(30)

\section{Lawesson's reagent}

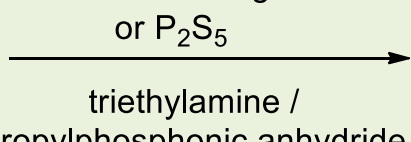

propylphosphonic anhydride

$80^{\circ} \mathrm{C} / 3-5 \mathrm{~h}$<smiles></smiles>

(31)

$\mathrm{R}_{1}=4-\mathrm{Br}-\mathrm{Ph} ; \mathrm{N}$-boc-azetidine-3-yl; 5-methyl-thiophen-2-yl; 5-Br-pyridin-3-yl; 1-naphthyl; N-Boc-aminoethyl

$\mathrm{R}_{2}=4-\mathrm{Bu}-\mathrm{Ph} ; 3-\mathrm{CH}_{3} \mathrm{O}-4-\mathrm{OH}-\mathrm{Ph} ; 2,4-\mathrm{Cl}-\mathrm{Ph} ; 5-\mathrm{Br}$-pyridin-3-yl; t-Bu; 4-Br-Ph; 3- $\mathrm{CH}_{3}-4-\mathrm{NO}_{2}-\mathrm{Ph} ; 3-\mathrm{F}-\mathrm{Ph}$

Scheme 6. Synthesis of thiadiazoles from carboxylic acids using propylphosphonic anhydride

\subsection{From dithiocarbazates}

Dithiocarbazates are synthesized by carbon disulfide as the sulfur source reagent reacting with hydrazine (32), hydrazides, thiosemicarbazide (13) or thioacylhydrazine usually under basic conditions (Scheme 7). ${ }^{17}$

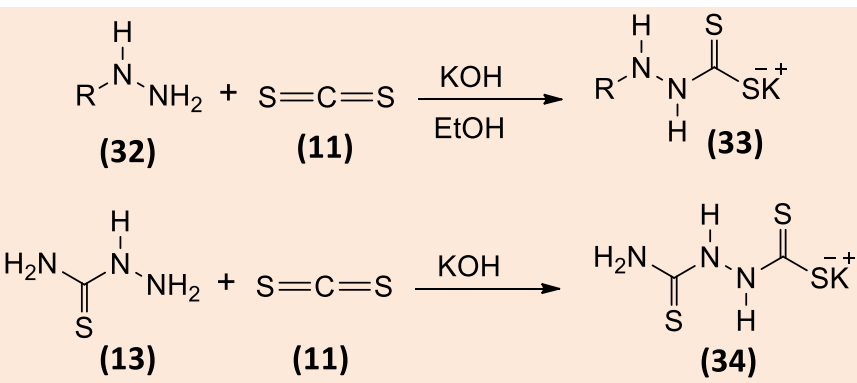

Scheme 7. Synthesis of dithiocarbazates from hydrazine derivatives

Literature reports the use of thiobenzhydrazide (35) and benzohydrazide (37) as the reagent to produce thiadiazole derivatives. Kubota and coworkers $(1970)^{45}$ described a reaction between benzamidrazone (39) and carbon disulfide
(11) to obtain the thiadiazole $\mathbf{4 0}$ with a yield of $82 \%$ (Scheme 8). The benzamidrazone was used by the authors due its structural similarity to $\mathbf{3 5}$ and $\mathbf{3 7}$. The reaction conditions employed by the authors favored 
the formation of $\mathbf{4 0}$ in a single step without the formation of the intermediate salt. ${ }^{45}$

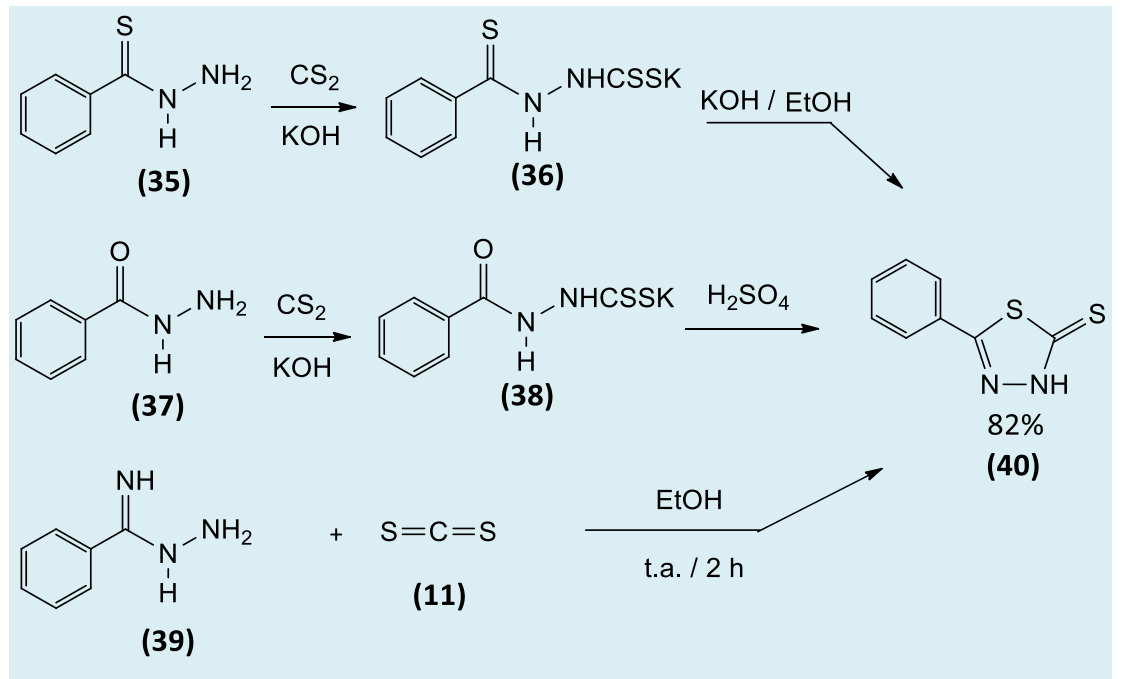

Scheme 8. Synthesis of 1,3,4-thiadiazoline-5-tione derivatives

In 2010, Gong et al. ${ }^{46}$ summarized several methods for solid-phase synthesis of 1,3,4thiadiazoles using $\mathrm{CS}_{2}$ in the presence of sodium hydride at room temperature to prepare various acyldithiocarbazate resins (42) and then cyclodehydrate to generate the 1,3,4-thiadiazole derivatives (43). They developed a simple and efficient solid-phase method able to facilitate the production of the 1,3,4-thiadiazoles and used resin as a solid support (Scheme 9). ${ }^{46}$

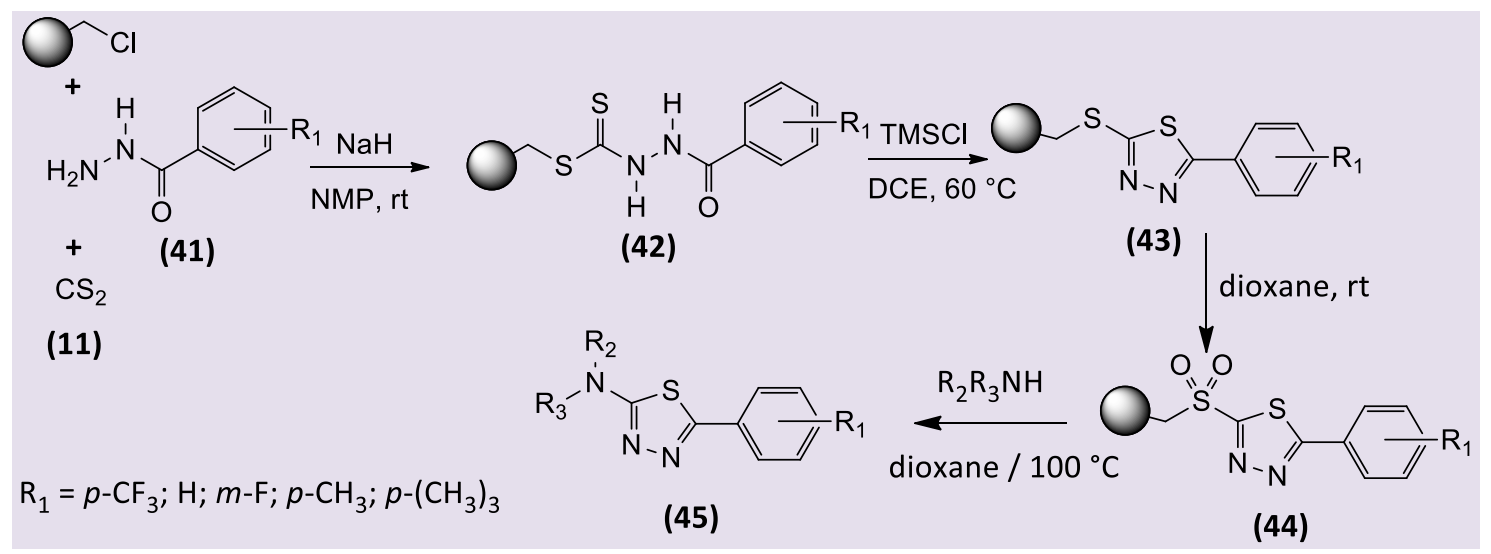

Scheme 9. Synthesis of 1,3,4-thiadiazoles using carbon disulfide and a solid support

These authors investigated various reagents for the cyclization reactions of the acyldithiocarbazates (42), including $\mathrm{N}$-(3dimethylaminopropyl)- $N^{\prime}$-ethylcarbodiimide $(E D C l), N, N^{\prime}$-dicyclohexylcarbodiimide (DCC), trimethylsilyl chloride (TMSCl), $p$ toluenesulfonyl chloride ( $\mathrm{TsCl})$, thionyl chloride, phosphorus pentachloride, and diphenyl chlorophosphate. The results indicated that $\mathrm{TMSCl}$ and diphenyl chlorophosphate were the best choices for the synthesis of 1,3,4-thiadiazoles (45) (Scheme 9). ${ }^{46}$ Then, to explore the diversity of this methodology, the authors used various amines to release the 1,3,4-thiadiazoles from the resin (Figure 3 ). ${ }^{46}$ 


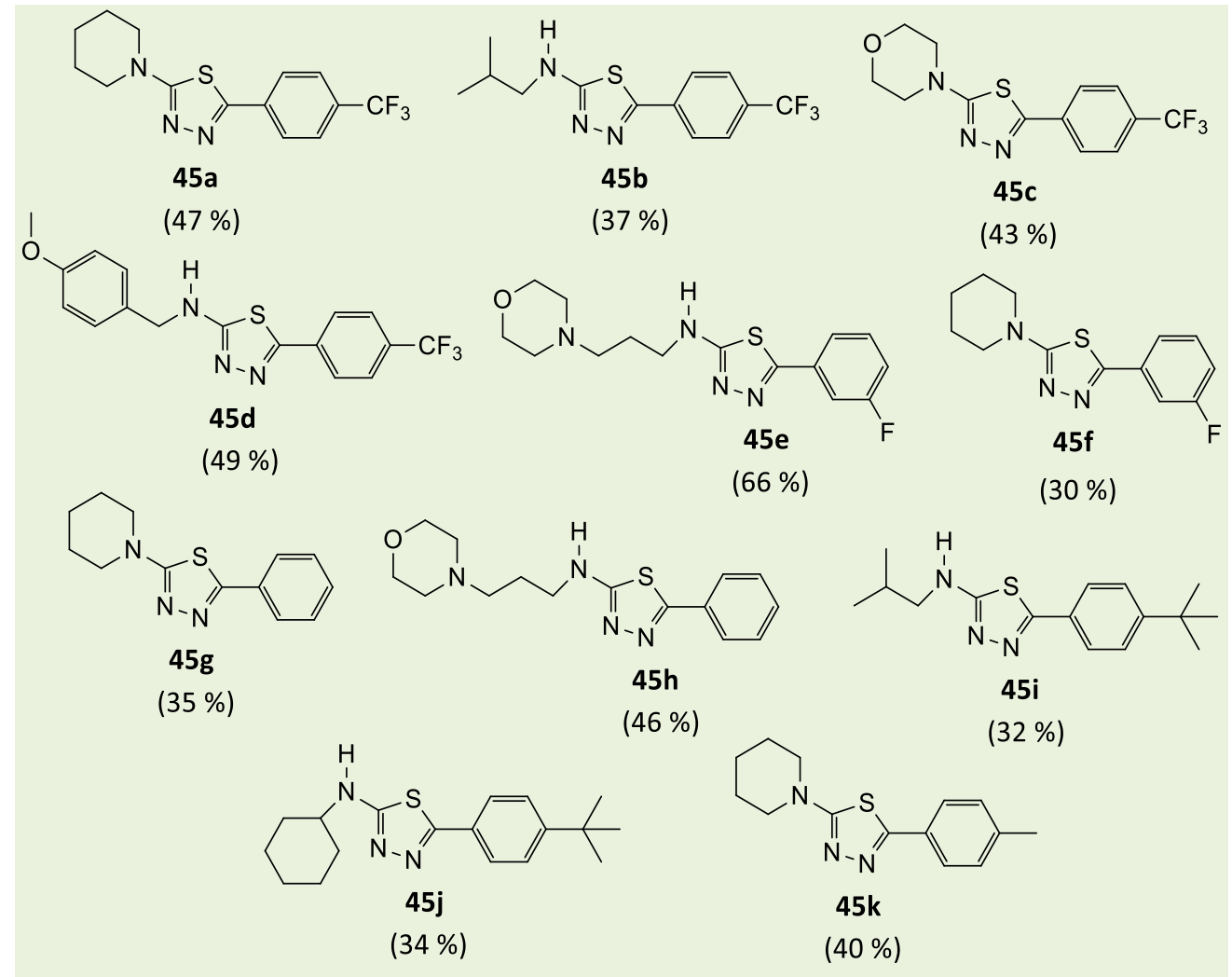

Figure 3. 1,3,4-thiadiazoles obtained and their yields

In 2011, Wang et al. ${ }^{47}$ synthetized 1,3,4thiadiazoles from dithiocarbazate. Dimethyl sulfate (46), carbon disulfide (11) and hydrazine hydrate (10) in the presence of potassium hydroxide reacted to generate the intermediate thiohydrazide (47). This intermediate reacted with chloroacetylchloride at a low temperature ($15{ }^{\circ} \mathrm{C}$ ) to produce compound 48 that was cyclized in $10 \%$ sodium bicarbonate to provide (5-methylthio-1,3,4-thiadiazol-2yl)methylchloride (49) in a yield of $78 \%$ (Scheme 10). ${ }^{47}$

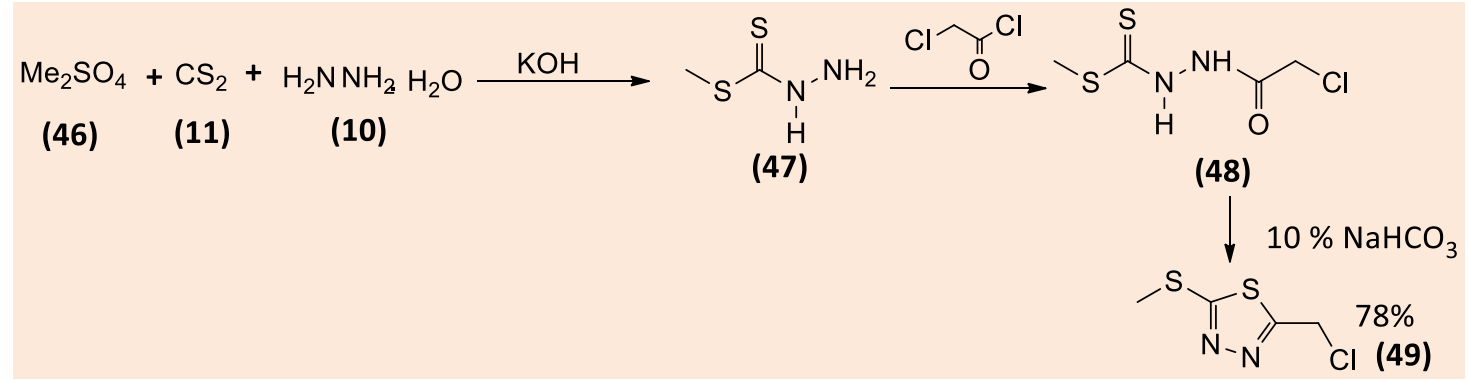

Scheme 10. Synthesis of 1,3,4-thiadiazoles from dithiocarbazate

A few years later, Sayed et al. used the hydrazonoyl bromide (50) with methyl hydrazinecarbodithioate (47) in ethanol to obtain 3-phenyl-5-(2-hydroxyphenyl)-1,3,4- thiadiazol-2-(3-amino)-imine (51) as the only isolated product by the removal of hydrogen bromide and methanethiol (Scheme 11). ${ }^{48}$ 


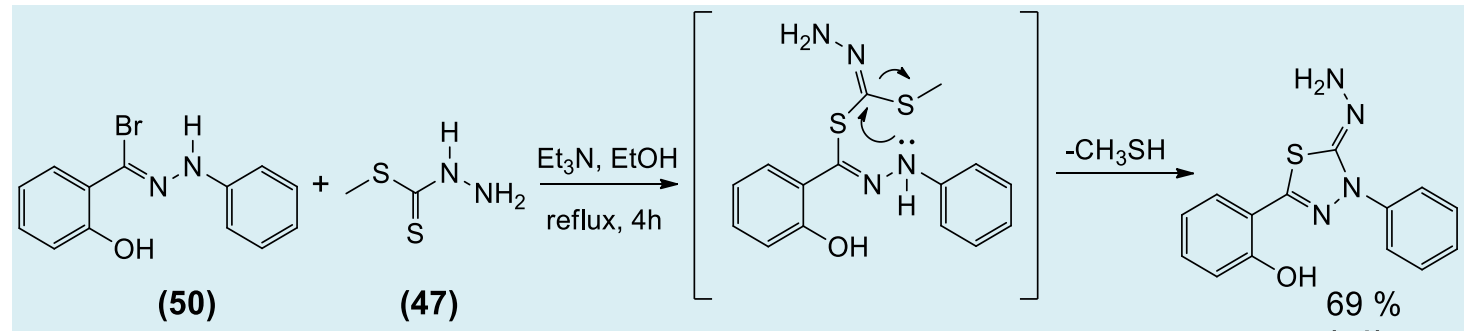

(51)

Scheme 11. Synthesis of compound $\mathbf{5 1}$ from dithiocarbazate and hydrazonoyl bromide

\subsection{From thiosemicarbazides}

Many syntheses of 1,3,4-thiadiazoles proceed from thiosemicarbazide cyclization, which have been widely used and are efficient in the formation of thiadiazoles. This reaction occurs according to the mechanism presented in Scheme $12 .{ }^{17}$ The proposed mechanism starts with a nucleophilic attack of the nitrogen electron pair of thiosemicarbazide to the carboxylic acid $\mathrm{sp}^{2}$ carbon, followed of dehydration of the intermediary. The sulfur atom electron pair attacks the carbonyl causing cyclization and the intermediary formed is then dehydrated. Finally, an electron migration produces the aromatic heterocycle.

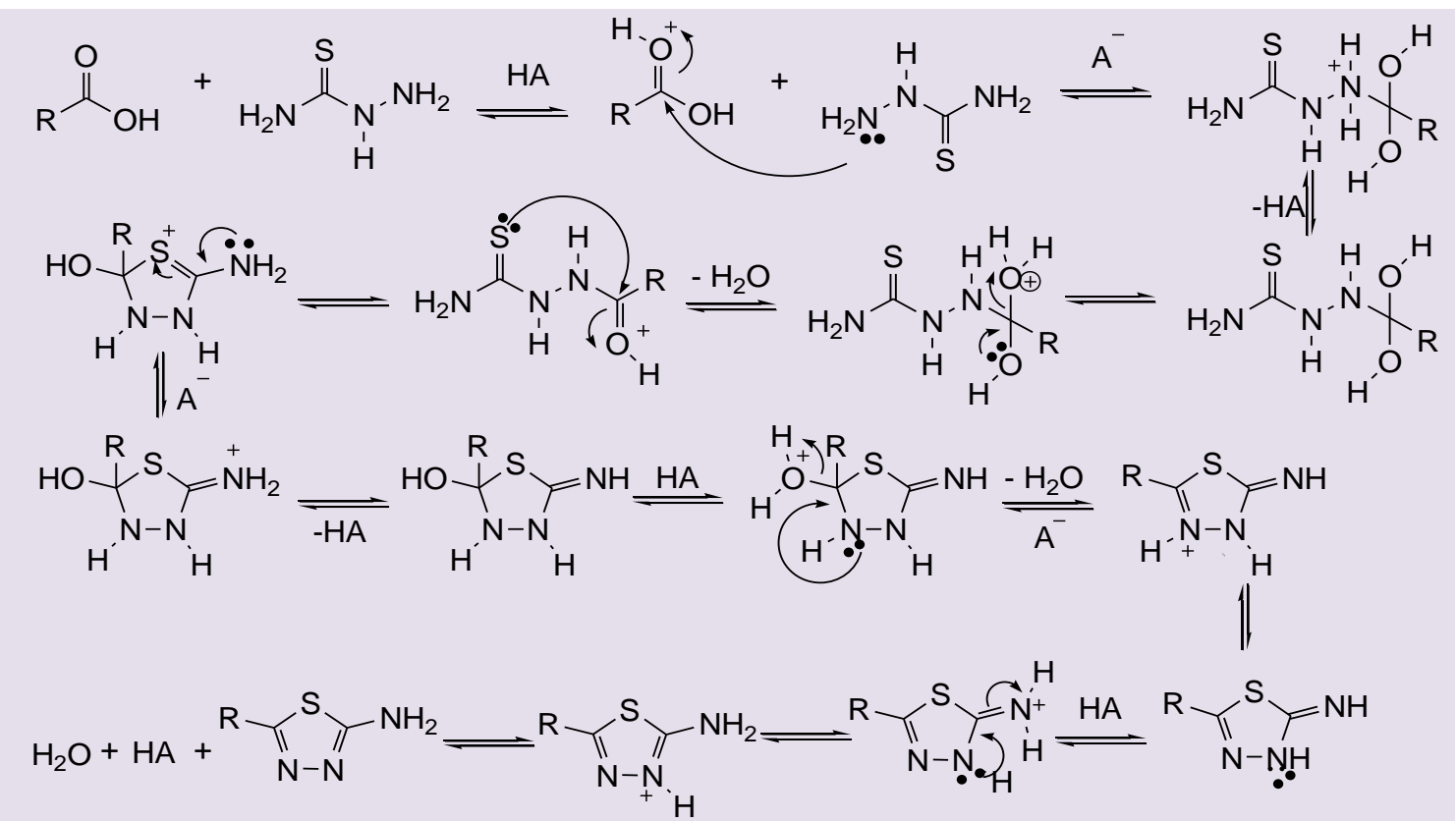

Scheme 12. Mechanism of cyclization of thiosemicarbazides ${ }^{17}$

The procedure performed by Hoggarth (1949) involved the treatment of thiosemicarbazide derivatives (52a-c) with phosphoric acid to form the thiadiazoles (53ac) with yields of $30-50 \%$ (Table1). ${ }^{30}$ 
Table 1. Synthesis of thiadiazoles from the cyclization of thiosemicarbazide derivatives

\begin{tabular}{ccc}
\hline & \\
\hline Compound (53) & $\mathrm{R}$ & Yields (\%) \\
\hline a & $-\mathrm{OCH}_{3}$ & 30 \\
c & $\mathrm{Cl}$ & 50 \\
\hline
\end{tabular}

In 1959, Chubb and Nissenbaum acid (54a-h) in the presence of sulfuric acid. synthesized 2-amino-5-substituted-1,3,4- The reaction was maintained at a temperature thiadiazole derivatives (55a-h) by the reaction of $80-90{ }^{\circ} \mathrm{C}$ for $7 \mathrm{~h}$ and the products were of a thiosemicarbazide (13) with carboxylic obtained in yields of $35-80 \%$ (Table 2). ${ }^{49}$

Table 2. Synthesis of thiadiazole derivatives obtained by Chubb and Nissenbaum ${ }^{49}$

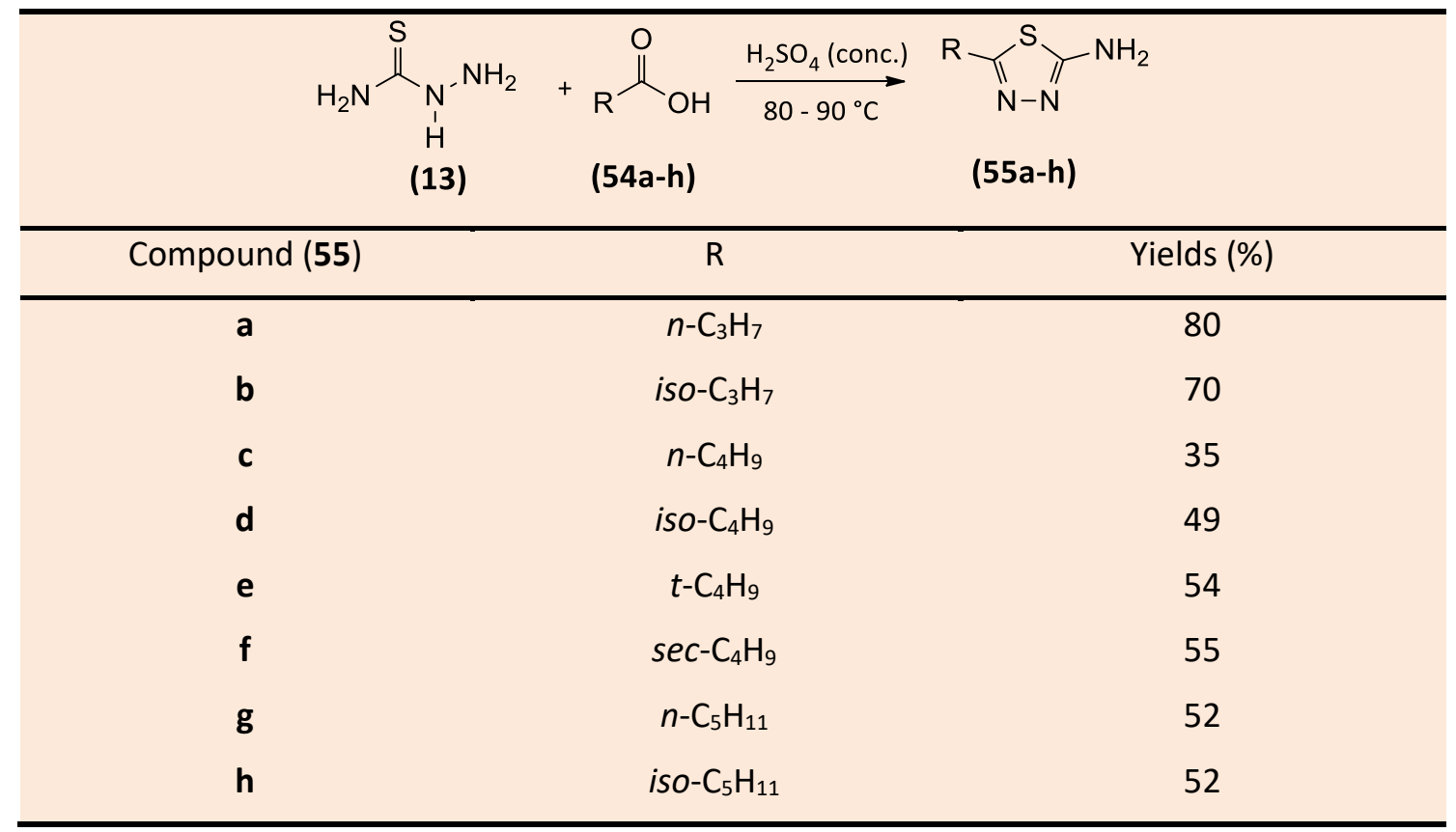

Years later, Kurzer and Canelle synthesized 1,3,4-thiadiazole derivatives employing a twostep methodology. This procedure involved the treatment of 1amidinothiosemicarbazides (56a-g) with acetic anhydride. This reaction yielded the intermediates (57a-g) in yields of $38-72 \%$. Acid hydrolysis of these intermediates provided 58 a-g in yields of 54-85 \% (Table 3). ${ }^{50}$ 
Table 3. Derivatives of 1,3,4-thiadiazoles obtained by Kurzer and Canelle $\mathrm{e}^{50}$

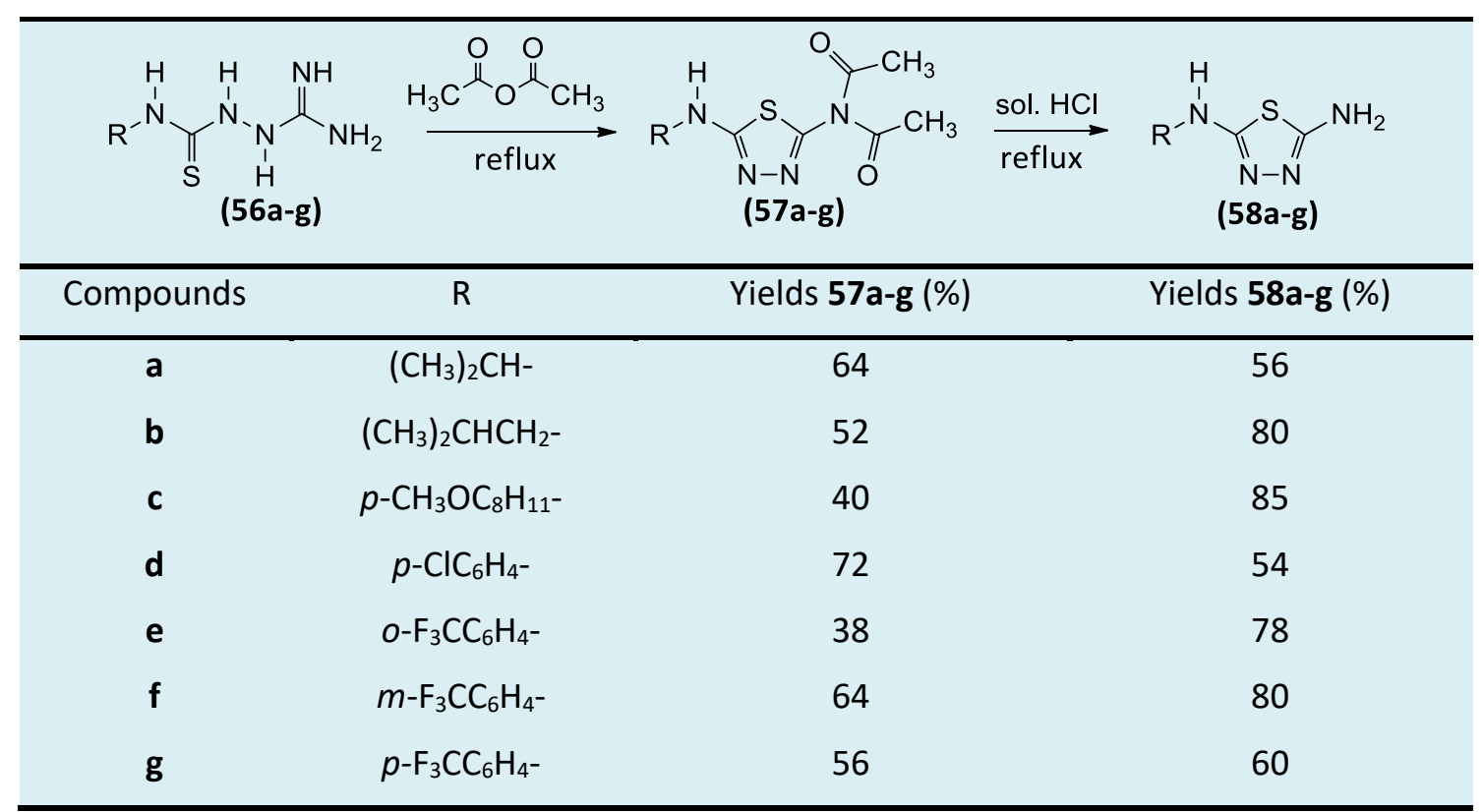

Rao and Srinivasan (1970) $)^{51}$ and Husain et al. $(1986)^{52}$ employed the same method used by Hoggarth (1949). Both authors treated arylthiosemicarbazide with concentrated sulfuric acid to form thiadiazoles (59a-e) in yields of $60-75 \%$ and $50-55 \%$, respectively (Table 4). ${ }^{51,52}$

Table 4. Reaction of thiosemicarbazide with sulfuric acid to produce thiadiazoles

\begin{tabular}{|c|c|c|c|}
\hline & 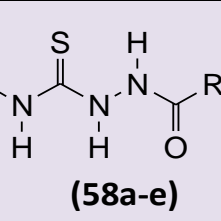 & 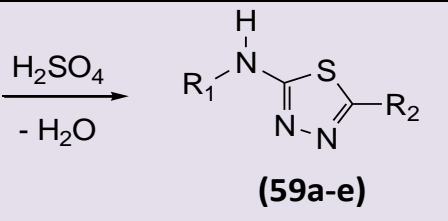 & \\
\hline Compound (59) & $\mathrm{R}_{1}$ & $\mathrm{R}_{2}$ & Yields (\%) \\
\hline$a^{51}$ & $\mathrm{H}$ & $3,4,5-(\mathrm{MeO})_{3}-\mathrm{C}_{6} \mathrm{H}_{2}$ & 60 \\
\hline $\mathbf{b}^{51}$ & $\mathrm{H}$ & $3,4-\mathrm{Cl}_{2}-\mathrm{C}_{6} \mathrm{H}_{3}$ & 72 \\
\hline$c^{51}$ & $\mathrm{H}$ & 2- $\mathrm{NO}_{2}-\mathrm{C}_{6} \mathrm{H}_{4}$ & 75 \\
\hline$d^{52}$ & $\mathrm{C}_{6} \mathrm{H}_{5}$ & $\beta$ - $\left(\mathrm{CH}_{2} \mathrm{O}\right)$-Naphthalene & 50 \\
\hline $\mathbf{e}^{52}$ & $\mathrm{CH}_{3} \mathrm{O}-\mathrm{C}_{6} \mathrm{H}_{4}$ & $\beta$ - $\left(\mathrm{CH}_{2} \mathrm{O}\right)$-Naphthalene & 55 \\
\hline
\end{tabular}

The results obtained with sulfuric acid were slightly better when compared to the results obtained by the procedure adopted by Hoggarth, using $\mathrm{H}_{3} \mathrm{PO}_{4}$. However, the compounds synthesized by Rao and Srinivasan presented better yields when compared to those of Husain et al. This difference may be related to the substitution pattern of $R 1$, since the insertion of the phenyl group may decrease the availability of electrons in the sulfur, due to the resonance between the aromatic ring and the nitrogen. ${ }^{30,51,52}$ However, it was not possible to compare this with the results of Chubb (1959), since the thiosemicarbazide used has no substitution. 
Palaska et al. (2002) reported the synthesis of 1,3,4-thiadiazole derivatives (62a-d) from the treatment of thiosemicarbazides with methanesulfonic acid. The reaction was conducted by refluxing toluene using a ratio of 1:15 of the reactants, respectively (Table 5). The authors reported low yields (15-31\%) for these transformations. ${ }^{53}$

Table 5. Cyclization of thiosemicarbazide derivatives using methanesulfonic acid

\begin{tabular}{|c|c|c|}
\hline$\underbrace{N_{1}^{O}}_{(61 a-d)}$ & $\mathrm{CH}_{3} \mathrm{SO}_{3} \mathrm{H}$ & $\begin{array}{l}\mathrm{S}^{\mathrm{N}} \\
\mathrm{H} \\
\mathrm{H}\end{array}$ \\
\hline Compound (62) & $\mathrm{R}$ & Yield (\%) \\
\hline a & $\mathrm{C}_{6} \mathrm{H}_{5}$ & 24 \\
\hline b & $\mathrm{C}_{2} \mathrm{H}_{5}$ & 31 \\
\hline c & $\mathrm{CH}_{3}$ & 25 \\
\hline d & $\mathrm{CH}_{2}-\mathrm{CH}=\mathrm{CH}_{2}$ & 15 \\
\hline
\end{tabular}

Since then, several authors have used dehydrative cyclization of thiosemicarbazides to obtain 1,3,4-thiadiazoles. The simplicity of the reagents and the experimental conditions allowed the use of the procedures described below with yields of between 50-90 \%. The most commonly used reagents were sulfuric acid and phosphorus oxychloride..$^{20,54-56}$
In 2010, Schüttelkopf et al. synthetized the acetazolamide derivative (64) from the reaction of thiosemicarbazide (13) and acetyl chloride (63). The mixture was stirred for $4 \mathrm{~h}$ at room temperature and the product was obtained with yield of $23 \%$ (Scheme 13). ${ }^{57}$

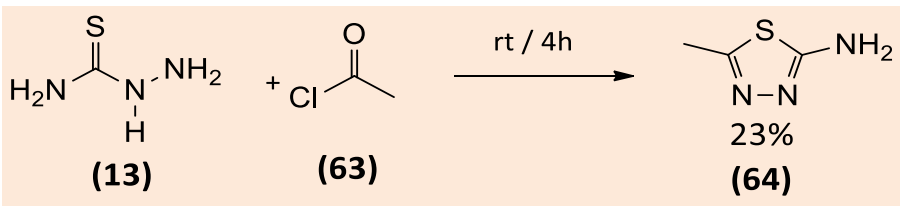

Scheme 13. Synthesis of 1,3,4-thiadiazole from acetyl chloride and thiosemicarbazide

According to Epishinaet al. $(2011)^{58}$, the methods to synthesize 2-amino-1,3,4thiadiazoles based on the cyclocondensation of carboxylic acids with thiosemicarbazide in an acidic medium, mostly in concentrated sulfuric acid, produce good results. In some cases, $\mathrm{POCl}_{3}, \mathrm{MeSO}_{3} \mathrm{H}$ in the presence of $\mathrm{P}_{2} \mathrm{O}_{5}$, polyphosphoric acid (PPA) and dichlorophosphate on polyethyleneglycole are used as acidic catalysts. However, they have some disadvantages, because a large amount of inorganic salts are generated in the neutralization of $\mathrm{H}_{2} \mathrm{SO}_{4}$ and the other acidic catalysts, which results in an adverse environmental impact and creates difficulties to isolate the final products. Furthermore, these reactions are suitable only for the synthesis of monocyclic compounds. ${ }^{58}$

The goal of these researchers was to develop a new general method for the preparation of 2-amino-1,3,4-thiadiazole derivatives. The authors evaluated carboxylic 
acids (65a-g) and thiosemicarbazide (13) for the preparation of 2-amino-1,3,4-thiadiazole derivatives (66a-g) in ionic liquids, which have been widely employed as potential substitutes of conventional solvents for a variety of chemical processes. ${ }^{58}$
According to the authors, a new, simple and general method was developed based on heating of carboxylic acids, including the $\mathrm{N}$ protected $\alpha$-amino acids, with thiosemicarbazide at $100{ }^{\circ} \mathrm{C}$ in ionic liquids with the addition of $\mathrm{H}_{2} \mathrm{SO}_{4}$ in a catalytic amount (Table 6). The reaction provided 66ag with yields of $40-96 \% .{ }^{17,58}$

Table 6. Synthesis of 1,3,4-thiadiazoles using ionic liquids as the solvent

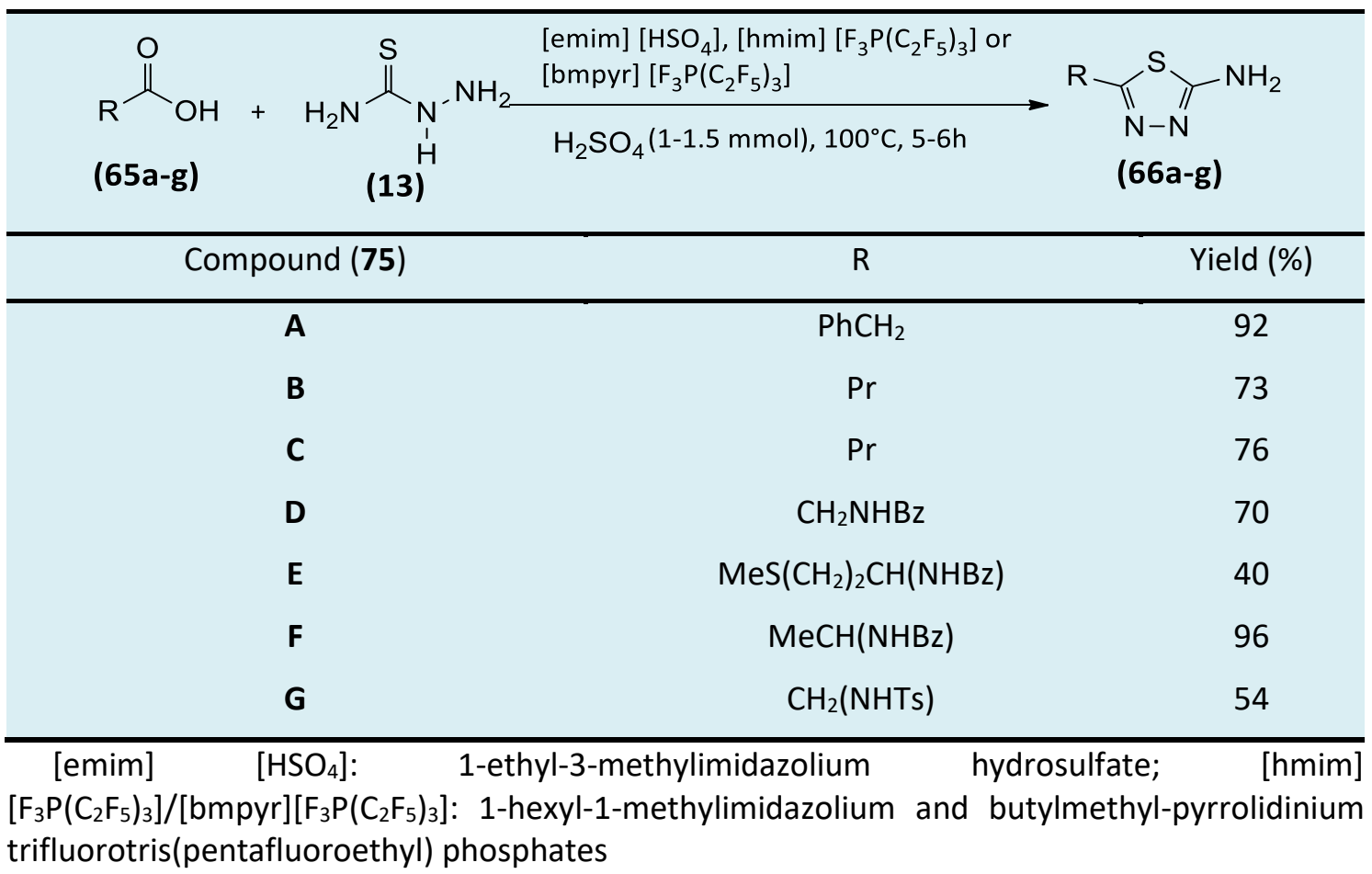

In 2013, Yang et al. developed an efficient method for the regioselective synthesis of 2amino-substituted 1,3,4-thiadiazoles or 1,3,4oxadiazoles by cyclodehydration or cyclodesulfurization reactions (Scheme 14).
Thiosemicarbazides (67), which serve as useful intermediates in this process, are generated by the reaction of the isothiocyanate starting material with acyl hydrazides. ${ }^{59}$

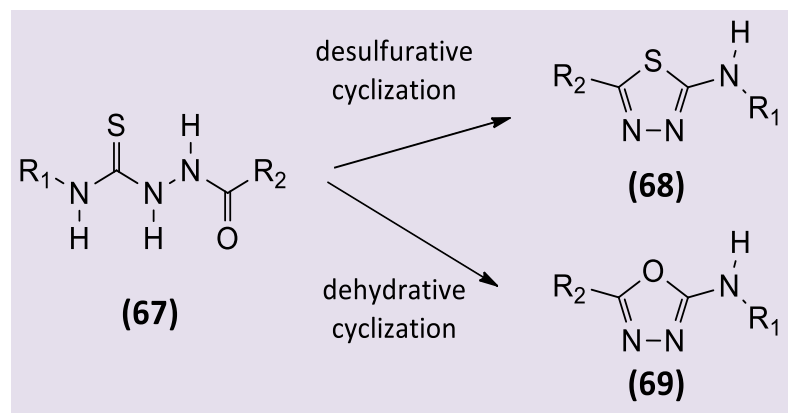

Scheme 14. Cyclization of the thiosemicarbazide 
To investigate the regioselectivity of the synthesis of 1,3,4-thiadiazoles (68a-f), cyclization reactions of thiosemicarbazide were investigated by using various reagents, for example, 1-ethyl-3-(3dimethylaminopropyl) carbodiimide $(\mathrm{EDC} \cdot \mathrm{HCl}), \quad p-\mathrm{TsCl}, \mathrm{TMSCl}$, and diphenyl chlorophosphate under various conditions. ${ }^{59}$

The use of EDC $\mathrm{HCl}$, which is well known as a desulfurizing agent, produced 2-amino- 1,3,4-oxadiazole (69a-f) as a major product with regioselectivity (100: 0 ) and a high yield (>99 \%). The TMSCl, and diphenyl chlorophosphate were not efficient. On the other hand, in the case of $p$-TsCl-based cyclization, various thiosemicarbazides showed different regioselectivity depending on the substituent. The best results are presented in Table 7. ${ }^{59}$

Table 7. Results of the cyclization with $p$-TsCl/TEA

\begin{tabular}{|c|c|c|c|c|c|}
\hline $\begin{array}{r}R_{1}-N \\
\text { (67) } \stackrel{!}{H}\end{array}$ & 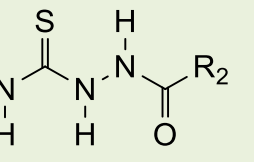 & $\underset{\mathrm{NMP}}{\stackrel{p-\mathrm{TsCl} / \mathrm{TEA}}{\longrightarrow}}$ & & $\mathrm{R}_{1}$ & \\
\hline \multirow{2}{*}{ Compound } & \multirow{2}{*}{$\mathrm{R}_{1}$} & \multirow{2}{*}{$\mathrm{R}_{2}$} & \multicolumn{2}{|c|}{ Ratio } & \multirow{2}{*}{ Yield (\%) } \\
\hline & & & 68 & 69 & \\
\hline$a$ & Benzyl & $\mathrm{Ph}$ & 96 & 4 & 92 \\
\hline b & Benzyl & 4-F-Ph & 99 & 1 & 87 \\
\hline c & Benzyl & $4-\mathrm{NO}_{2}-\mathrm{Ph}$ & 99 & 1 & 63 \\
\hline d & 4-methoxy-Bn & $\mathrm{Ph}$ & 96 & 4 & 73 \\
\hline e & Ethyl & $\mathrm{Ph}$ & 97 & 3 & 94 \\
\hline$f$ & $\begin{array}{l}\text { 2,4-dimethoxy- } \\
\text { Benzyl }\end{array}$ & $4-\mathrm{NO}_{2}-\mathrm{Ph}$ & 99 & 1 & 87 \\
\hline
\end{tabular}

Niu et al. (2015) synthesized 2-aminosubstituted 1,3,4-thiadiazoles (71a-j) via condensation of thiosemicarbazide (13) and the corresponding aldehydes (70a-j) followed by $\mathrm{I}_{2}$-mediated oxidative $\mathrm{C}-\mathrm{S}$ bond formation (Scheme 15). ${ }^{60}$ After condensation of the thiosemicarbazide and the corresponding aldehyde, the reaction mixture was concentrated and then redissolved in 1,4dioxane, followed by treatment with molecular iodine and potassium carbonate to form the respective thiadiazoles. ${ }^{60}$

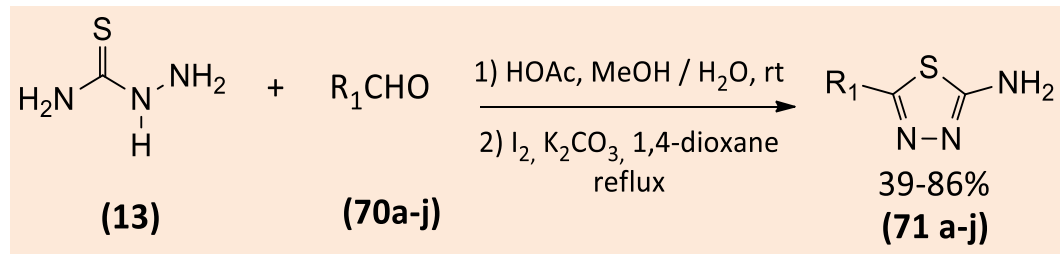

Scheme 15. Synthesis of 2-amino-1,3,4-thiadiazoles employing $I_{2}$

This transition-metal-free sequential aliphatic, and cinnamic aldehydes to provide a synthesis process is compatible with aromatic, series of 2-amino-1,3,4-thiadiazole derivatives 
Barbosa, G. A. D.; de Aguiar, A. P.

with moderate to good yields (Table 8). ${ }^{60}$ According to the authors, under the optimal sequential synthesis conditions, thiosemicarbazide and the corresponding aldehydes were smoothly converted into the desired thiadiazoles without purification of the condensation intermediates. ${ }^{60}$

Table 8. Derivatives of 1,3,4-thiadiazoles obtained by Niu et al ${ }^{60}$

\begin{tabular}{ccc}
\hline Compound (71a-j) & $\mathbf{R}_{\mathbf{1}}$ & Yield (\%) \\
\hline a & $p-\mathrm{CH}_{3}-\mathrm{Ph}$ & 81 \\
b & $m-\mathrm{CF}_{3}-\mathrm{Ph}$ & 86 \\
$\mathbf{c}$ & $p-\mathrm{NO}_{2}-\mathrm{Ph}$ & 74 \\
$\mathbf{d}$ & $p-$ methoxy-Ph & 54 \\
$\mathbf{e}$ & $p-\mathrm{Cl}-\mathrm{Ph}$ & 60 \\
$\mathbf{f}$ & $p-\mathrm{CN}-\mathrm{Ph}$ & 65 \\
$\mathbf{g}$ & $o-\mathrm{F}-\mathrm{Ph}$ & 84 \\
$\mathbf{h}$ & $2,4-\mathrm{Cl}-\mathrm{Ph}$ & 81 \\
$\mathbf{i}$ & $t-\mathrm{Bu}_{2}$ & 76 \\
$\mathbf{j}$ & $-\mathrm{CH}_{2}=\mathrm{CH}_{2}-\mathrm{Ph}$ & 39 \\
\hline
\end{tabular}

Noolvi et al. (2016) reacted some enones (72a-q) and thiosemicarbazide in the presence of glacial acetic acid and ethanol to produce the intermediates $\mathbf{7 3 a - q}$, which were cyclized by treating with thiosemicarbazide and $\mathrm{POCl}_{3}$ or polyphosphoric acid (PPA). This last step provided 74a-q with yields of $20-70 \%$ (Table 9). ${ }^{61}$

In 2018, Altintop et al. reported the synthesis of the some thiadiazoles employing the thiosemicarbazide $\mathbf{7 5}$ and carbon disulfide. The intermediate 76 was synthesized by the ring closure reaction of 4[4-(trifluoromethyl)phenyl]thiosemicarbazide (75) with carbon disulfide in the presence of potassium hydroxide (Scheme 16). Finally, the reaction of 76 with $\mathrm{N}$-(aryl)-2chloroacetamides in the presence of potassium carbonate afforded new 1,3,4thiadiazoles (77) with yields between 78$92 \% .^{8}$ 
Table 9. Synthesis of 1,3,4-thiadiazoles from thiosemicarbazide and $\mathrm{POCl}_{3}$ or PPA

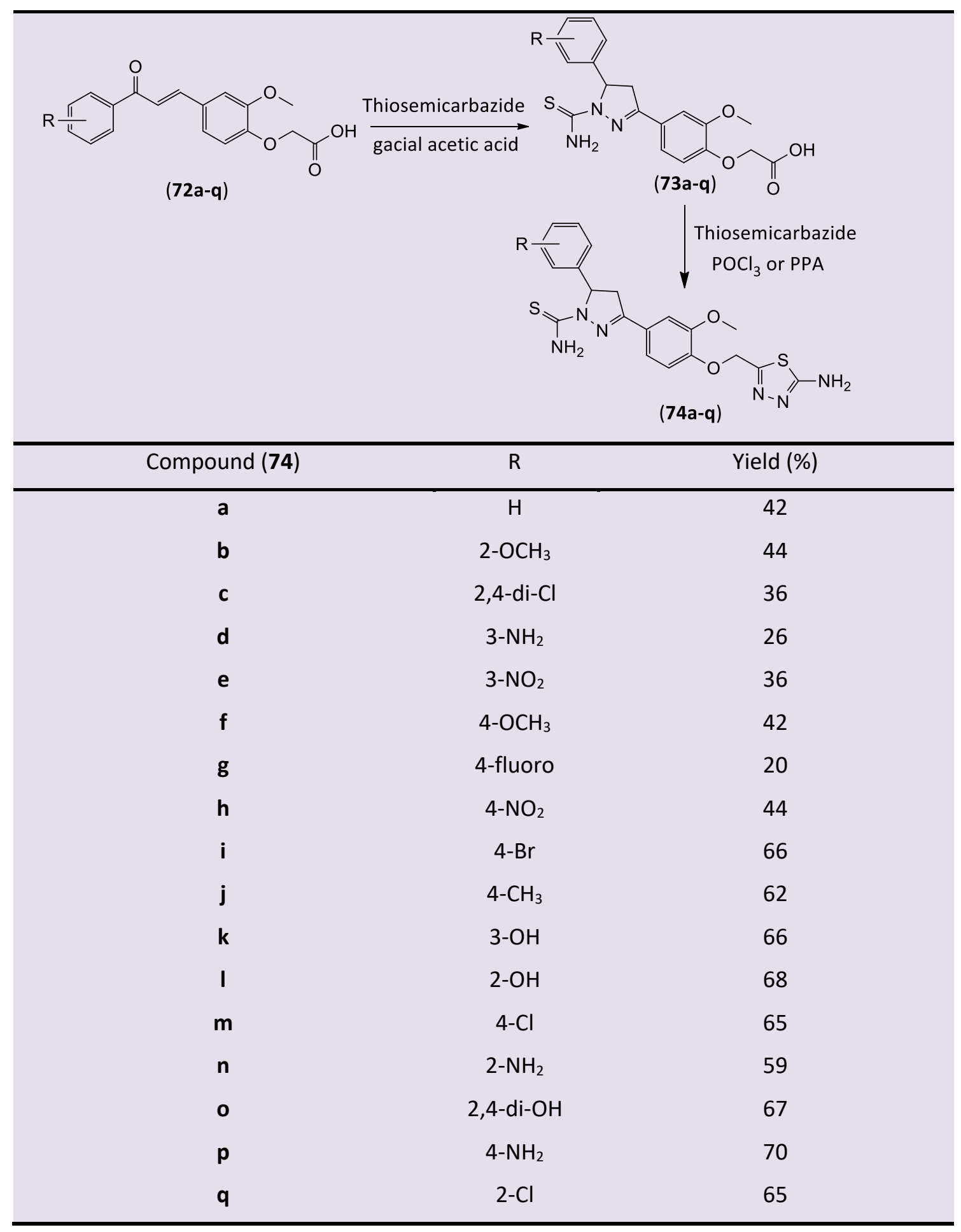


Barbosa, G. A. D.; de Aguiar, A. P.

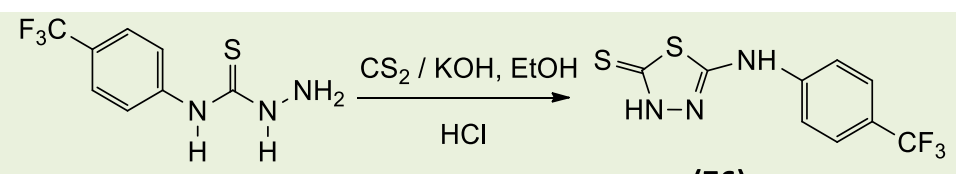

(75)<smiles>[R][CH]Cc1nccs1</smiles><smiles>CC(C)c1ncc([N+](=O)[O-])s1</smiles>

$(78 \%)$

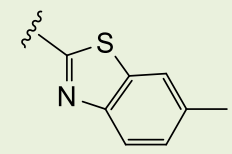

$(81 \%)$

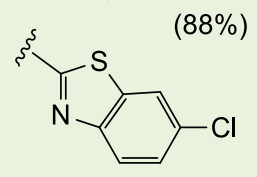

(90\%)

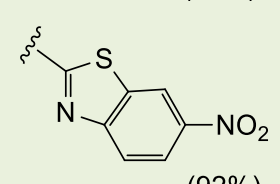

$(92 \%)$
(76)<smiles>[R]NC(=O)CCCCC(C)OC(=O)O</smiles><smiles>[R]NC(=O)CSc1nnc(Nc2ccc(C(F)(F)F)cc2)s1</smiles>

(77)

Scheme16. Synthesis of 1,3,4-thiadiazoles employing thiosemicarbazide and $\mathrm{CS}_{2}$

Recently, Yuanet al. (2018) reported the synthetic routes for the synthesis of $[1,2,4]$ triazolo[3,4-b] $[1,3,4]$ thiadiazole derivatives $(\mathbf{8 0} \mathbf{a}-\mathbf{b})$. The compounds were prepared from a two-step cyclization of 2-(4hydroxyphenyl) acetic acid (78) with thiocarbohydrazide (13) and carboxylic acids. 2-(4-hydroxyphenyl)acetic hydrazinecarbothiohydrazide methanesulfonic acid were dissolved in sulfolane/water and the solution was stirred at $90{ }^{\circ} \mathrm{C}$ for $24 \mathrm{~h}$. The intermediate (79) obtained was then treated with carboxylic acid in sulfolane and $\mathrm{POCl}_{3}$. The reaction mixture was stirred at $85{ }^{\circ} \mathrm{C}$ for $18 \mathrm{~h}$. Both products were obtained in $27 \%$ yields (Scheme 17). ${ }^{62}$

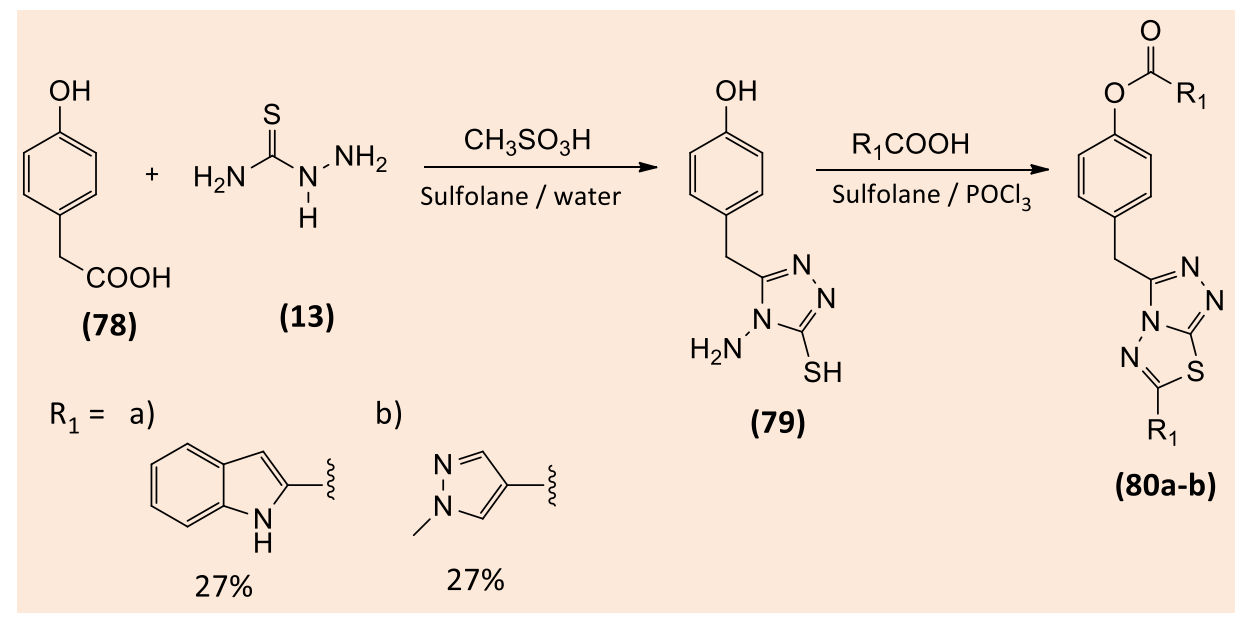

Scheme 17. Synthesis of $[1,2,4]$ triazolo[3,4-b][1,3,4]thiadiazole derivatives

\subsection{From thiosemicarbazone}

Young \& Eyre (1901) developed a methodology for the synthesis of 1,3,4thiadiazole (82) through the oxidation of aryl thiosemicarbazone (81) using an aqueous solution of ferric chloride (Scheme 18). According to the authors, the oxidation of thiosemicarbazone by ferric chloride occurs under milder reaction conditions $\left(70-80{ }^{\circ} \mathrm{C}\right)$ when compared to the oxidation of semicarbazone $\left(130-140{ }^{\circ} \mathrm{C}\right) .^{28}$ 


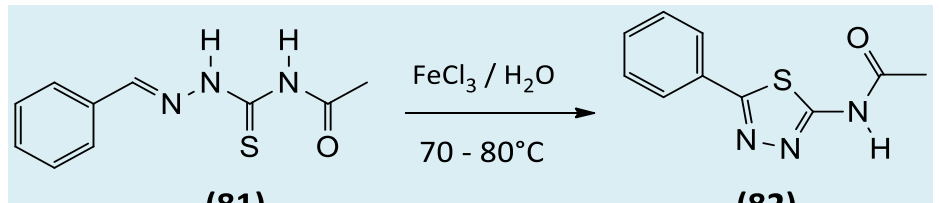

(81)

(82)

Scheme 18. Oxidation of phenyl thiosemicarbazone with $\mathrm{FeCl}_{3}$ to produce 1,3,4-thiadiazoles

Years later, Skagius et al. (1960) employed the methodology developed by Young \& Eyre (1901) to synthesize 84 (Scheme 19). ${ }^{63}$ The authors reported good performance in the oxidation of 5-nitrofurfural thiosemicarbazone (83) with ferric chloride, ${ }^{28,53,58} \quad$ however when thiosemicarbazones derived from 2-furfural and 2-pyridine-carboxaldehyde were used, the yields obtained were less than $40 \%$. The authors associated the lower yield obtained in the reaction with furfural, compared to 5nitrofurfural, with the nitro group which prevents the acid cleavage of the furan ring. ${ }^{63}$

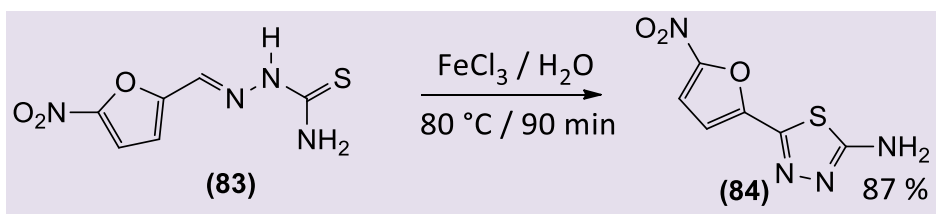

Scheme 19. Synthesis of 1,3,4-thiadiazole with heteroaromatic substituents employing $\mathrm{FeCl}_{3}$

In 1970, in order to optimize the methodology, Rao and Srinivasan investigated the process of oxidative cyclization of arylthiosemicarbazone using ferric chloride (Scheme 20). ${ }^{51}$

In 1970, Rao and Srinivasan investigated the synthesis of 2-amino-5-aryl-1,3,4thiadiazole derivatives by oxidative cyclization of aldehyde thiosemicarbanozes with ferric chloride, dehydrative cyclization of 1acylthiosemicarbazides with sulfuric acid and direct amination of monoaryl-1,3,4thiadiazoles using hydroxylamine hydrochloride. The authors reported more satisfactory results using a homogenous reaction mixture. In this case, the aqueous solution of ferric chloride was replaced by an alcohol solution. The authors suggested that thiosemicarbazone oxidation involved the formation of a radical intermediate (Scheme 20), giving the thiadiazole ring (85a-f) yields of between $44-91 \%$ (Table 10). ${ }^{51}$

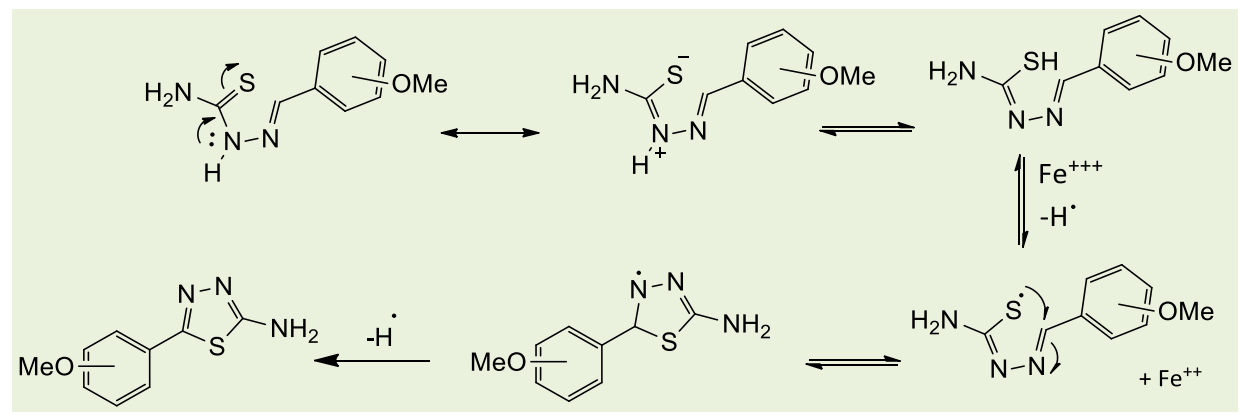

Scheme 20. Mechanistic scheme for the oxidation of thiosemicarbazone 
Barbosa, G. A. D.; de Aguiar, A. P.

Table 10. Yield of the thiadiazole derivatives obtained by Rao andSrinivasan ${ }^{51}$

\begin{tabular}{ccc}
\hline & & \\
& & \\
\hline Compound (85) & & \\
\hline a & $\mathrm{R}$ & Yield (\%) \\
b & $2-\mathrm{f})$ & 61 \\
c & $2-\mathrm{CeO}_{6} \mathrm{H}_{5}$ & 91 \\
d & $4-\mathrm{CeO}_{6} \mathrm{H}_{4}$ & 46 \\
e & $3,4-(\mathrm{MeO})_{2}-\mathrm{C}_{6} \mathrm{H}_{3}$ & 65 \\
f & $2-\mathrm{Cl}-\mathrm{C}_{6} \mathrm{H}_{4}$ & 87 \\
\hline
\end{tabular}

Foroumadi et al. (2001) reported the synthesis of 1,3,4-thiadiazoles (87a-b) through the oxidative cyclization reaction of 2 aryl-thiosemicarbazones (86a-b) using ammonium ferric sulfate dodecahydrate as the oxidizing agent. Heterocycles were obtained in yields of $77 \%$ and $85 \%$ (Scheme21). ${ }^{64}$

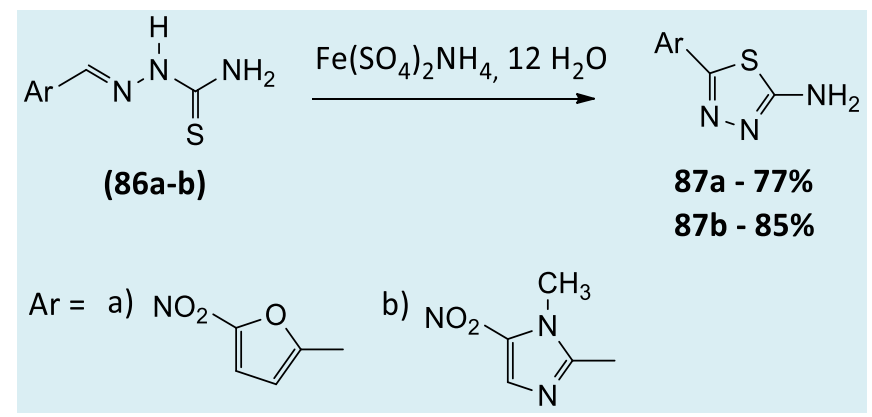

Scheme 21. Synthesis of 1,3,4-thiadiazoles from thiosemicarbazone and $\mathrm{Fe}\left(\mathrm{SO}_{4}\right)_{2} \mathrm{NH}_{4}$

In 2008, Li et al. report a new route for the preparation of (un)substituted benzaldehyde (5-aryl-1,3,4-thiadiazol-2-yl) hydrazones (90ak) from thiosemicarbazones (88a-k) and aromatic carboxylic acids (89a-k). These authors reported yields between $80-90 \%$ when silica-supported dichlorophosphate was used as a recoverable dehydrant under microwave irradiation (Table11). ${ }^{65}$ 
Table 11. Synthesis of benzaldehyde (5-aryl-1,3,4-thiadiazol-2-yl) hydrazones (90a-k)

\begin{tabular}{|c|c|c|c|}
\hline & 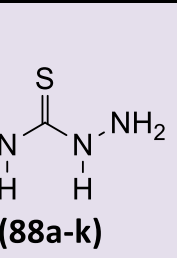 & $\mathrm{MW}$ & 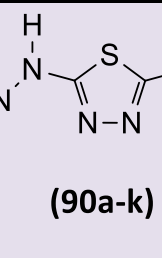 \\
\hline $\begin{array}{c}\text { Compound } \\
(90)\end{array}$ & $\mathrm{R}_{1}$ & $\mathrm{R}_{2}$ & Yield (\%) \\
\hline a & $\mathrm{H}$ & $\mathrm{H}$ & 90 \\
\hline b & $\mathrm{H}$ & $4-\mathrm{CH}_{3} \mathrm{O}$ & 87 \\
\hline c & $\mathrm{H}$ & $2-\mathrm{CH}_{3}$ & 80 \\
\hline d & $\mathrm{H}$ & $3-\mathrm{CH}_{3}$ & 84 \\
\hline e & $\mathrm{H}$ & $3-\mathrm{Cl}$ & 84 \\
\hline$f$ & $\mathrm{H}$ & $4-\mathrm{Cl}$ & 82 \\
\hline $\mathbf{g}$ & $4-\mathrm{CH}_{3} \mathrm{O}$ & $\mathrm{H}$ & 85 \\
\hline h & $4-\mathrm{CH}_{3} \mathrm{O}$ & $4-\mathrm{CH}_{3} \mathrm{O}$ & 87 \\
\hline $\mathbf{i}$ & $4-\mathrm{CH}_{3} \mathrm{O}$ & $4-\mathrm{Cl}$ & 83 \\
\hline j & $4-\mathrm{CH}_{3} \mathrm{O}$ & $3-\mathrm{Cl}$ & 84 \\
\hline k & $4-\mathrm{CH}_{3} \mathrm{O}$ & $2-\mathrm{CH}_{3}$ & 81 \\
\hline
\end{tabular}

In 2013, Feng et al. ${ }^{66}$ synthesized 2-amino5-aryl-1,3,4-thiadiazole derivatives (92a-g) from the cyclization of thiosemicarbazone in the presence of $\mathrm{FeCl}_{3}$. However, for more efficient and more environmentally friendly methods, the research group chose to synthesize 1,3,4-thiadiazole through microwave irradiation and ultrasound, without the use of organic solvents or acidic conditions (Table 12). The solution of thiosemicarbazone, ferric chloride and water was subjected to microwave $(200 \mathrm{~W})$ and ultrasound $(50 \mathrm{~W})$ for 3 minutes, to generate the products with $73-90 \%$ yields (Table 12). ${ }^{66}$ 
Barbosa, G. A. D.; de Aguiar, A. P.

Table 12. Oxidative cyclization of thiosemicarbazones in ferric chloride using microwave irradiation

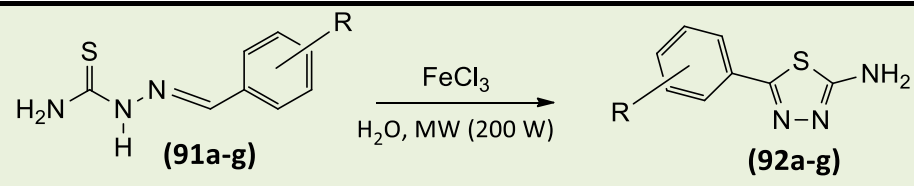

\begin{tabular}{ccc}
\hline Compound (92) & $\mathrm{R}$ & Yield (\%) \\
\hline a & $\mathrm{H}$ & 85 \\
b & $4-\mathrm{F}$ & 90 \\
c & $3-\mathrm{NO}_{2}$ & 89 \\
d & $4-\mathrm{Cl}$ & 85 \\
e & $2,4-\mathrm{Cl}$ & 84 \\
f & $4-\mathrm{CH}_{3}$ & 73 \\
g & $4-\mathrm{OCH}_{3}$ & 88 \\
\hline
\end{tabular}

Kariyappa and Gurunanjappa (2016) cyclization of thiosemicarbazone (93a-f) using reported a synthesis of novel compounds bromine dissolved in glacial acetic acid for 2-3 (94a-f) that were obtained by the oxidative $h$ at room temperature (Table 13). ${ }^{67}$

Table 13. Oxidative cyclization of thiosemicarbazones using bromine-glacial acetic acid

\begin{tabular}{ccc}
\hline Compound (94) & Yield (\%) \\
\hline b & $\mathrm{Cr}$ & 82 \\
c & $4-\mathrm{Cl}_{6} \mathrm{C}_{6} \mathrm{H}_{4}$ & 80 \\
d & $2-\mathrm{CH}_{3}-\mathrm{C}_{6} \mathrm{H}_{4}$ & 76 \\
e & $2-\mathrm{OCH}_{3}-\mathrm{C}_{6} \mathrm{H}_{4}$ & 79 \\
f & $2,4-\left(\mathrm{CH}_{3}\right)_{2}-\mathrm{C}_{6} \mathrm{H}_{3}$ & 78 \\
\hline
\end{tabular}

As can be seen, the oxidative cyclization of thiosemicarbazone is a fast and efficient methodology that provides yields of up to $90 \%$, as well as the cyclization by dehydration of thiosemicarbazides, and is used to date in the synthesis of 1,3,4-thiadiazoles intermediates. ${ }^{10,35,67,68}$ 


\subsection{From 1,3,4-oxadiazole}

An alternative methodology reported in the literature is associated with the conversion of oxadiazole to thiadiazole. The $1,3,4$-oxadiazole ring is a bioisosteric analogue of the 1,3,4-thiadiazole ring. The substitution of oxygen for sulfur in the heterocyclic ring represents an example of an approach that is commonly known as bioisosterism. The idea of bioisosterism is one of the most successful techniques of bioactive compound design. ${ }^{69-71}$
However, the conversion of oxadiazole to thiadiazole has limited use due to the need for longer reaction times $(30 \mathrm{~h})$ compared to the previously reported processes, ranging from 0.5 to $7 \mathrm{~h}$.

Linganna and Rai (1998) synthesized 1,3,4thiadiazoles (96a-d) from the oxadiazole reaction with a solution of thiourea in tetrahydrofuran (Table 14). The authors reported yields of 55-69\%, but the reaction time was long $(24-30 \mathrm{~h}) .^{31}$

Table 14. Reaction for the conversion of aryl-1,3,4-oxadiazole to aryl-1,3,4-thiadiazoles

\begin{tabular}{|c|c|c|c|}
\hline Compound (96) & $\mathrm{R}$ & $\mathrm{R}_{1}$ & Yields (\%) \\
\hline a & $\mathrm{C}_{6} \mathrm{H}_{5}$ & $\mathrm{C}_{6} \mathrm{H}_{5}$ & 65 \\
\hline b & $\mathrm{C}_{6} \mathrm{H}_{5}$ & $\left(\mathrm{CH}_{3} \mathrm{O}\right)-\mathrm{C}_{6} \mathrm{H}_{4}$ & 60 \\
\hline c & $\mathrm{C}_{6} \mathrm{H}_{5}$ & $\left(\mathrm{CH}_{3} \mathrm{O}\right)_{3}-\mathrm{C}_{6} \mathrm{H}_{2}$ & 69 \\
\hline d & $\left(\mathrm{NO}_{2}\right)-\mathrm{C}_{6} \mathrm{H}_{4}$ & $\left(\mathrm{CH}_{3} \mathrm{O}\right)_{3}-\mathrm{C}_{6} \mathrm{H}_{2}$ & 55 \\
\hline
\end{tabular}

According to the authors, the probable mechanism of the reaction is due to the attack of the sulfur atom from thiourea on the heterocycle followed by the ring opening, as described in Scheme $22 .{ }^{31}$

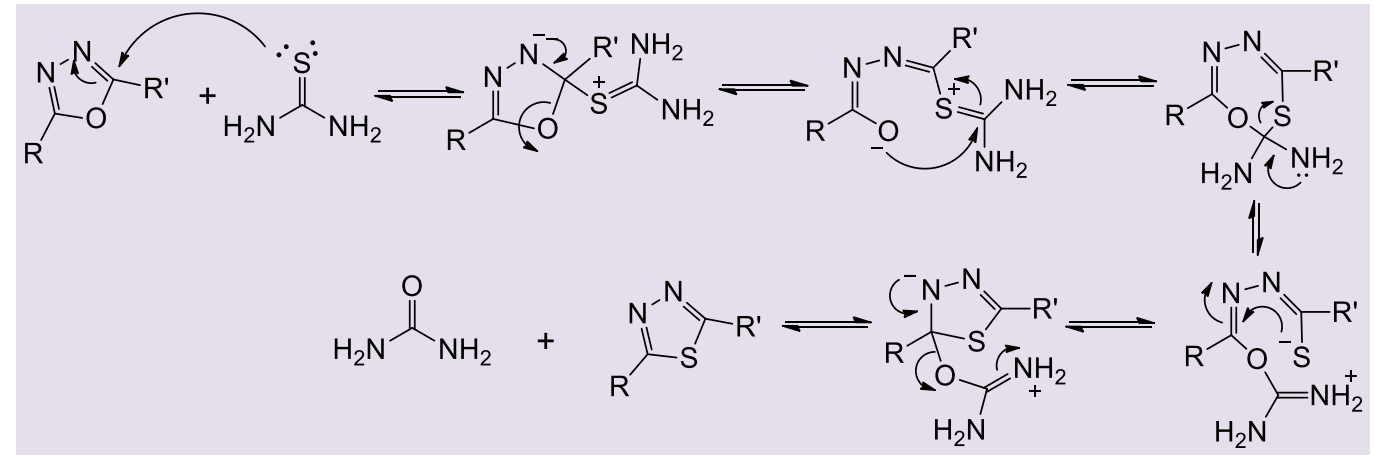

Scheme 22. Mechanistic scheme proposed by Linganna and Rai

Although its use is more restricted, in the last 10 years, Padmavathi and his research group have employed this methodology. Their reports showed yields between $64-78 \%$, although the reaction time ranged from 20 to 30 h. $14,38,72-74$ 


\section{1,3,4-Thiadiazoles: Microbiological Activities}

The planning, synthesis and evaluation of the bioactivity of molecules with therapeutic potential has been the target of organic and pharmaceutical chemistry. Moreover, the heterocyclic compounds have been the focus of much research in the field of Medicinal Chemistry. ${ }^{20,35,75-77}$

Khalaj et al. $(2011)^{78}$ evaluated thiadiazole derivatives with analogous structures of linezolid (97) (Figure4). The results obtained were compared with the activity of linezolid and ciprofloxacin, which were used as reference antibiotics. ${ }^{78}$

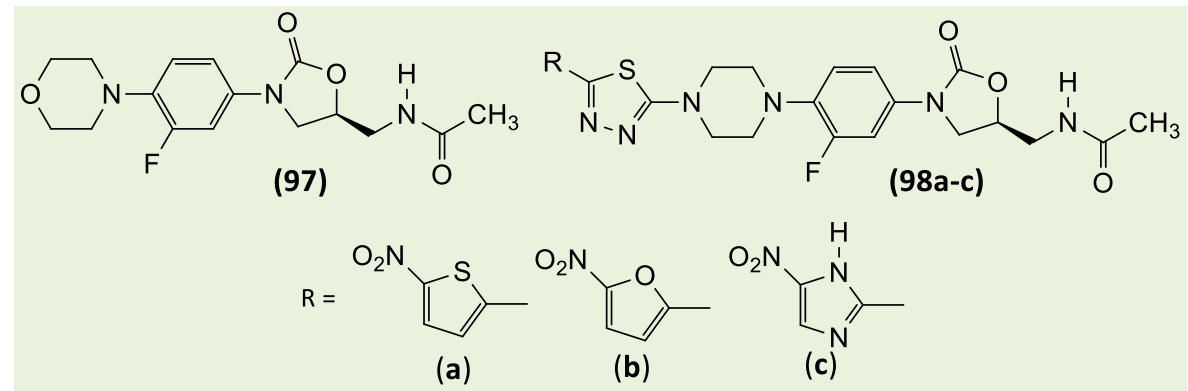

Figure 4. Thiadiazole analogous to linezolid

These derivatives (98a-c) were evaluated against Gram-positive bacteria (Staphylococcus aureus ATCC 6538p, Staphylococcus epidermidis ATCC 12228, Staphylococcus warneri, Staphylococcus lentus, Staphylococcus xylosus, Staphylococcus saprophyticus, Micrococcus luteus, Corynebacterium glutamicum and Bacillus subtilis, MRSA 3, MRSA 5 and MRSA 17 ) and Gram-negative bacteria (Escherichia coli ATCC 8739, Klebsiella pneumonia ATCC 10031 and Pseudomonas aeruginosa ATCC 9027).
The evaluated compounds presented MIC values similar to the reference antibiotic (linezolid - MIC> $100 \mu \mathrm{g} / \mathrm{mL}$ ) for Pseudomonas aeruginosa and Escherichia coli. The assays employing Gram-negative bacteria presented MICs between 0.78 and $100 \mu \mathrm{g} / \mathrm{mL}$. For Staphylococcus the MIC varied between 0.006 and $0.195 \mu \mathrm{g} / \mathrm{mL}$. All MIC values were lower than the reference antibiotics (linezolid). The compounds were efficient against resistant strains of Staphylococcus aureus, which had MIC values between 0.012 and $6.5 \mu \mathrm{g} / \mathrm{mL}$ (Table 15). ${ }^{78}$ 
Table 15. Results of the antibacterial evaluation of compounds 98a-c

\begin{tabular}{|c|c|c|c|c|c|}
\hline & \multirow{2}{*}{ Microorganism } & \multicolumn{4}{|c|}{ Minimum Inhibitory Concentration $(\mu \mathrm{g} / \mathrm{mL})$} \\
\hline & & $98 a$ & $98 \mathrm{~b}$ & $98 c$ & Linezolid \\
\hline \multirow{12}{*}{ 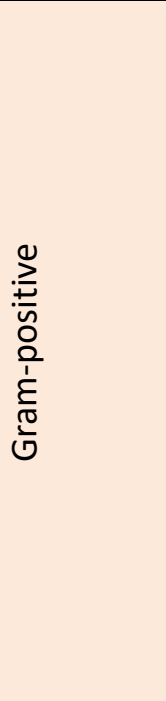 } & S. aureus & 0.098 & 0.012 & 0.098 & 0.781 \\
\hline & S. epidermidis & 0.024 & 0.006 & 0.024 & 0.781 \\
\hline & S. warnei & 0.049 & 0.006 & 0.006 & 0.781 \\
\hline & S. lentus & 0.098 & 0.012 & 0.098 & 1.563 \\
\hline & S. xylosus & 0.098 & 0.024 & 0.049 & 0.781 \\
\hline & S. saprophyticus & 0.195 & 0.024 & 0.024 & 0.781 \\
\hline & M. luteus & 6.25 & 0.391 & 0.195 & 0.781 \\
\hline & C. glutamicum & 6.25 & 0.195 & 0.195 & 0.781 \\
\hline & B. subtilis & 0.781 & 0.391 & 0.098 & 0.391 \\
\hline & MRSA 3 & 0.195 & 0.049 & 0.391 & 0.781 \\
\hline & MRSA 5 & 6.25 & 0.195 & 0.195 & 0.781 \\
\hline & MRSA 17 & 0.098 & 0.012 & 0.024 & 0.781 \\
\hline \multirow{3}{*}{ 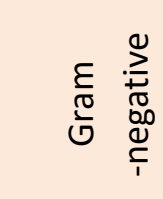 } & E. coli & $>100$ & $>100$ & $>100$ & $>100$ \\
\hline & K. pneumonia & 100 & 50 & 0.781 & 6.25 \\
\hline & P. aeruginosa & $>100$ & $>100$ & $>100$ & $>100$ \\
\hline
\end{tabular}

Barbuceanu et al. (2012) investigated biological activity of the derivatives of compounds 99a-b and 100a-b (Figure 5). The authors determined the MIC values for these derivatives, which were compared against the reference antimicrobials (fluconazole and amikacin). ${ }^{79}$

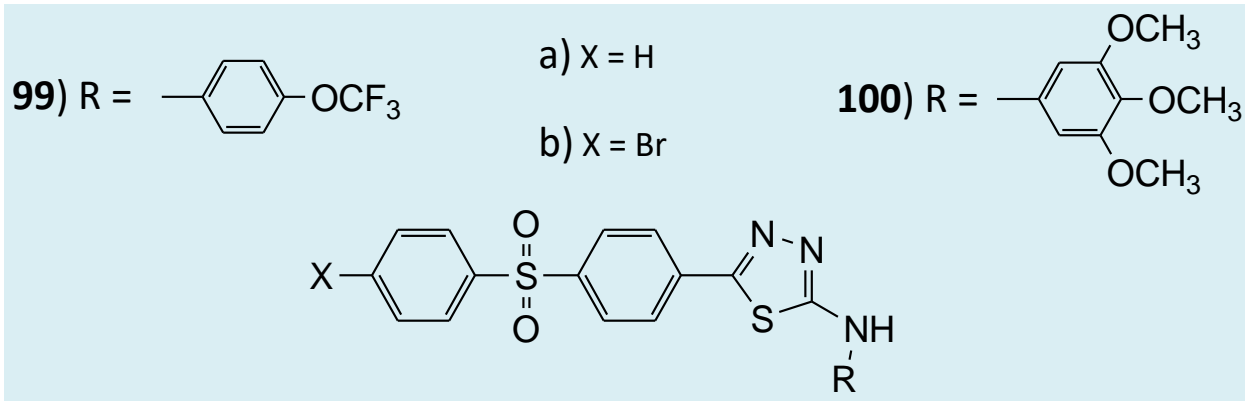

Figure 5. 1,3,4-thiadiazole class bearing diphenyl sulfone moieties with antimicrobial activity

The compounds showed antimicrobial activity (Table 16), however the concentrations presented were higher than 16 $\mu \mathrm{g} / \mathrm{mL}$. The best results were for Bacillus cereus bacteria with $\mathrm{MIC}$ values between 16$32 \mu \mathrm{g} / \mathrm{mL}$, since the reference antibiotic (amikacin) had no activity. ${ }^{79}$ 
Barbosa, G. A. D.; de Aguiar, A. P.

Table 16. Minimal Inhibitory Concentration of thiadiazole derivatives reported by Barbuceanuet $a l^{79}$

\begin{tabular}{ccccccccc}
\hline \multirow{2}{*}{ Compound } & \multicolumn{7}{c}{$\mathrm{MIC}(\mu \mathrm{g} / \mathrm{mL})^{a, b}$} \\
\cline { 2 - 9 } & $S a$ & $B c$ & $E c$ & $E c l$ & $A b$ & $P a$ & $C a$ & $C p$ \\
\hline 99a & 512 & 32 & 128 & 128 & 32 & 64 & 64 & 64 \\
99b & 512 & 32 & 128 & 128 & 32 & 64 & 128 & 64 \\
100a & 512 & 16 & 128 & 128 & 32 & 64 & 64 & 64 \\
100b & 512 & 16 & 64 & 128 & 32 & 64 & 64 & 64 \\
Amikacin & 2 & NA & 2 & NA & NA & 2 & NT & NT \\
Fluconazole & NT & NT & NT & NT & NT & NT & NA & 2 \\
\hline
\end{tabular}

${ }^{a}$ Sa - Staphylococcus aureus; Bc - Bacillus cereus; Ec - Escherichia coli; Ecl - Enterobacter cloacae;

Ab-Acinetobacter baumanni; Pa - Pseudomonas aeruginosa; Ca - Candida albicans;

$\mathrm{Cp}$ - Candida parapsilosis; ${ }^{b} \mathrm{NA}=$ no activity; NT = not tested

Chandrakantha et al. (2014) evaluated in the derivatives (101a-h) was evaluated by the vitro compounds in antibacterial and well plate method (Table 17). ${ }^{80}$ antifungal studies. Antibacterial activity for

Table 17. Results of the antimicrobial evaluation of compounds (101a-h)

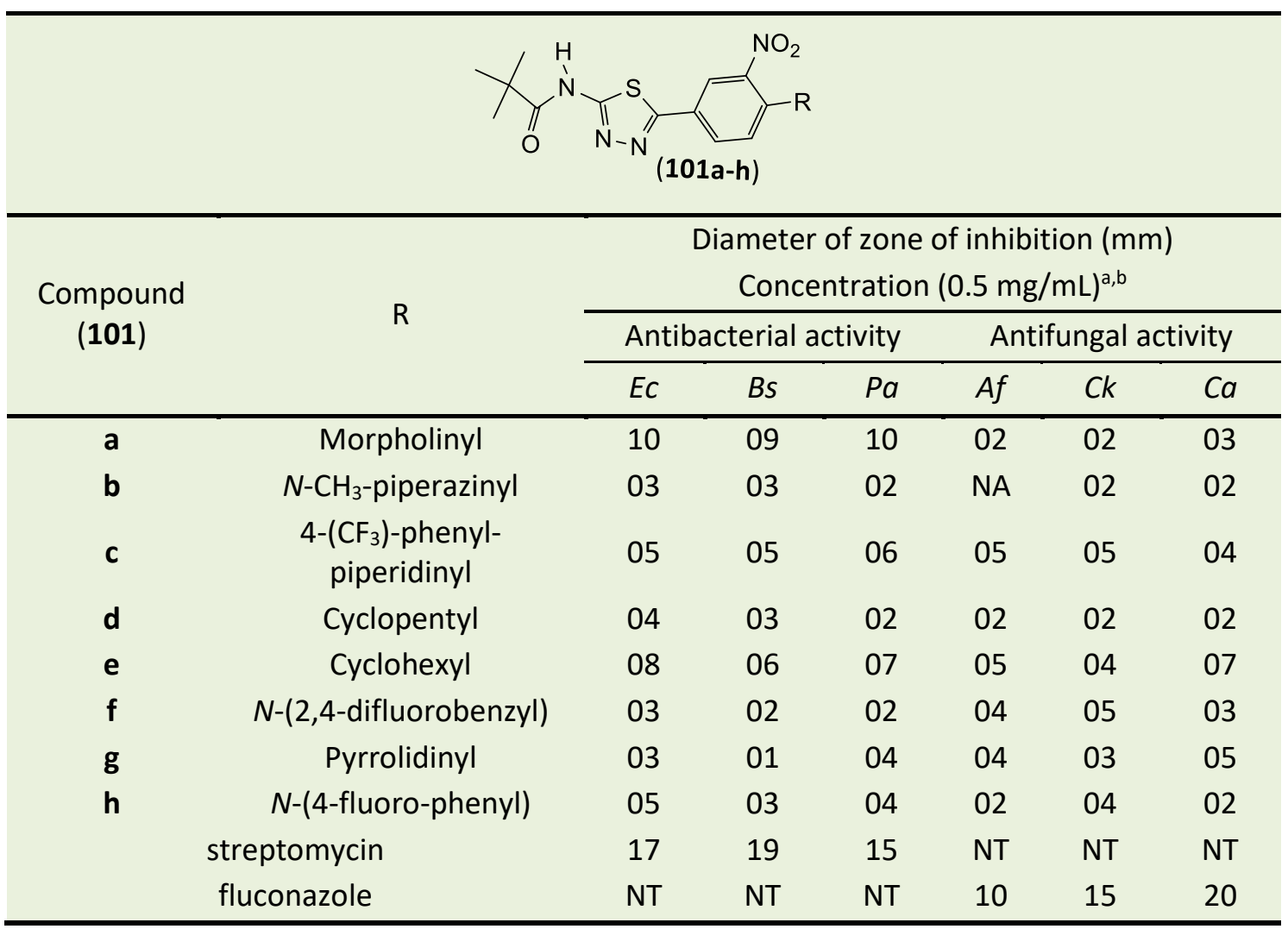

${ }^{a} E c$ - Escherichia coli; Bs - Bacillus subtillis; Pa - Pseudomonas aeruginosa; Af - Aspergillus flavus;

Ck - Chrysosporium keratinophilum; Ca - Candida albicans;

${ }^{\mathrm{b}} \mathrm{NA}=$ no activity; NT = not tested 
The compounds were tested against Gramnegative bacteria (Escherichia coli, Bacillus subtilis and Pseudomonas aeruginosa) and fungi (Candida albicans, Aspergillus flavus and Chrysosporium keratinophilum) according to Table $17 .{ }^{80}$ The preliminary in vitro antimicrobial screening of new 1,3,4thiadiazole derivatives evidenced that many of the compounds have emerged as potent antibacterial and antifungal agents with moderate activity compared to the standards. ${ }^{80}$

The antibacterial screening revealed that compound 101a showed good inhibition against various of the microbial strains tested, mainly, against Escherichia coli compared to the reference antibiotic (streptomycin). The remaining compounds showed moderated activity against the three bacterial strains tested. In the antifungal screening, compound 101c showed moderate activity against
Aspergillus flavus compared with the standard drug fluconazole. Whereas other compounds showed less activity against all the microorganisms tested compared to the standards. ${ }^{80}$

Kariyappa and Gurunanjappa (2016) ${ }^{67}$ performed microbial studies with various 1,3,4-thiadiazole derivatives (94a-f). The authors evaluated the minimum inhibitory concentration (MIC) of these derivatives using the serial dilution method. The compounds were tested against Gram-negative bacteria, Escherichia coli and Pseudomonas aeruginosa, Gram-positive bacterium, Staphylococcus aureus and fungi Aspergillus niger, Aspergillus flavus and Candida albicans. The antibiotics ciprofloxacin and fluconazole were used as standards for antibacterial and antifungal studies, respectively. Results of the MIC values are summarized in Table $18 .{ }^{67}$

Table 18. Bioactivity of 1,3,4-thiadiazole derivatives synthesized by Kariyappa and Gurunanjappa ${ }^{67}$

\begin{tabular}{|c|c|c|c|c|c|c|c|}
\hline \multirow{3}{*}{$\begin{array}{l}\text { Compound } \\
\text { (94) }\end{array}$} & \multirow{3}{*}{$\mathrm{R}$} & \multicolumn{6}{|c|}{ Minimum Inhibitory Concentration $(\mu \mathrm{g} / \mathrm{mL})^{a}$} \\
\hline & & \multicolumn{3}{|c|}{ Antibacterial activity } & \multicolumn{3}{|c|}{ Antifungal activity } \\
\hline & & S.aureus & $\begin{array}{c}E . \\
\text { coli }\end{array}$ & P.aeruginosa & A.niger & A.flavus & C.albicans \\
\hline $\bar{a}$ & $\mathrm{H}$ & 25 & 25 & 50 & 25 & 25 & 50 \\
\hline b & $4-\mathrm{Cl}$ & 12.5 & 12.5 & 12.5 & 12.5 & 25 & 25 \\
\hline c & $2-\mathrm{CH}_{3}$ & 25 & 50 & 12.5 & 25 & 50 & 25 \\
\hline d & $2-\mathrm{OCH}_{3}$ & 50 & 12.5 & 25 & 12.5 & 25 & 50 \\
\hline e & $2,4-\mathrm{CH}_{3}$ & 50 & 25 & 25 & 25 & 25 & 50 \\
\hline f & $\begin{array}{l}2,4- \\
\mathrm{NO}_{2}\end{array}$ & 50 & 100 & 75 & 100 & 50 & 50 \\
\hline \multicolumn{2}{|c|}{ ciprofloxacin } & 25 & 12.5 & 12.5 & NT & NT & NT \\
\hline \multicolumn{2}{|c|}{ fluconazole } & NT & NT & NT & 12.5 & 25 & 25 \\
\hline
\end{tabular}

${ }^{\mathrm{a} N T}=$ not tested 
The synthesized 1,3,4-thiadiazole compounds demonstrated moderate to excellent antibacterial and antifungal activity, inhibiting the organisms tested. The halogenated compound $\mathbf{9 4 b}$ showed excellent antibacterial activity against all organisms tested and higher activity against Staphylococcus aureus compared to ciprofloxacin. However, the nitro compound 94f presented the lowest activity against all the microorganisms tested. ${ }^{67}$

Compounds 94a and 94d, without substitution and containing a methoxy group, exhibited moderate activity against the fungi species tested, while the chlorinated heterocycle 94b showed excellent activity. Compound 94f, with nitro substitution, showed less activity against the fungi tested than the other compounds. ${ }^{67}$

The effect of the substitution on the aromatic ring of the synthesized compounds was studied based on their results of antimicrobial activity in vitro. The replacement of monochloro in 1,3,4thiadiazole, 94b, showed good antimicrobial activity, suggesting that the orthomonochloro substitution plays a very important role in hampering the cellular architecture of Escherichia coli, Pseudomonas. aeruginosa, Staphylococcus aureus and the fungi species Aspergillus niger, Aspergillus flavus and Candida albicans. The results suggest that 94b could actively inhibit the growth of Gram positive (S. aureus) and Gram negative bacteria (E. coli and $P$. aeruginosa) ${ }^{67}$

Noolvi et al. (2016) ${ }^{61}$ synthesized 1,3,4thiadiazole derivatives (74a-p) that were evaluated in antibacterial and antifungal in vitro studies using the agar diffusion method. The compounds were tested against different bacterial cultures Staphylococcus aureus, Salmonella enterica, Vibrio cholera, Bacillus subtilis, Proteus mirabilis, Escherichia coliV517, Mycobacterium smegmatis, Pseudomonas aeruginosa and one fungal culture Candida albicans (Table 19). ${ }^{61}$

Compounds $\mathbf{7 4 e}, \mathbf{7 4 g}, \mathbf{7 4 h}$ and $\mathbf{7 4 q}$ showed activities against all strains, while $74 \mathrm{e}$ and $\mathbf{7 4 h}$, with nitro substitution, showed high activity against Salmonella enterica (93.2 \% and $97 \%$ ) and Proteus mirabilis ( $80 \%$ and $87.3 \%$ ). In addition, the results were very close to the reference antibiotic (ampicillin). Compound 74k showed higher inhibition (87.1\%) against Staphylococcus aureus than the other compounds. Compound $\mathbf{7 4 0}$ was found to be active (96.5\% inhibition) against Escherichia coli V517 and 74p showed $90.2 \%$ and $83.1 \%$ inhibition against Pseudomonas aeruginosa and Mycobacterium smegmatis, respectively. The other 1,3,4-thiadiazole derivatives showed moderate antimicrobial activity compared to the standards. ${ }^{61}$

The replacement of nitro in 1,3,4thiadiazole $\mathbf{7 4 e}$ and $\mathbf{7 4 h}$ showed excellent antimicrobial activity, suggesting that 3-nitro and 4-nitro substitution plays a very important role in hampering the cellular architecture of Salmonella enterica and Proteus mirabilis. In addition, the 1,3,4-thiadiazole derivatives 74e and $74 \mathrm{~h}$ showed the best inhibition $183.3 \%$ and $87.8 \%$ and) against the fungal strain Candida albicans. ${ }^{61}$ 
Table 19. Bioactivity of thiadiazole derivatives evaluated by Noolvi et al ${ }^{61}$

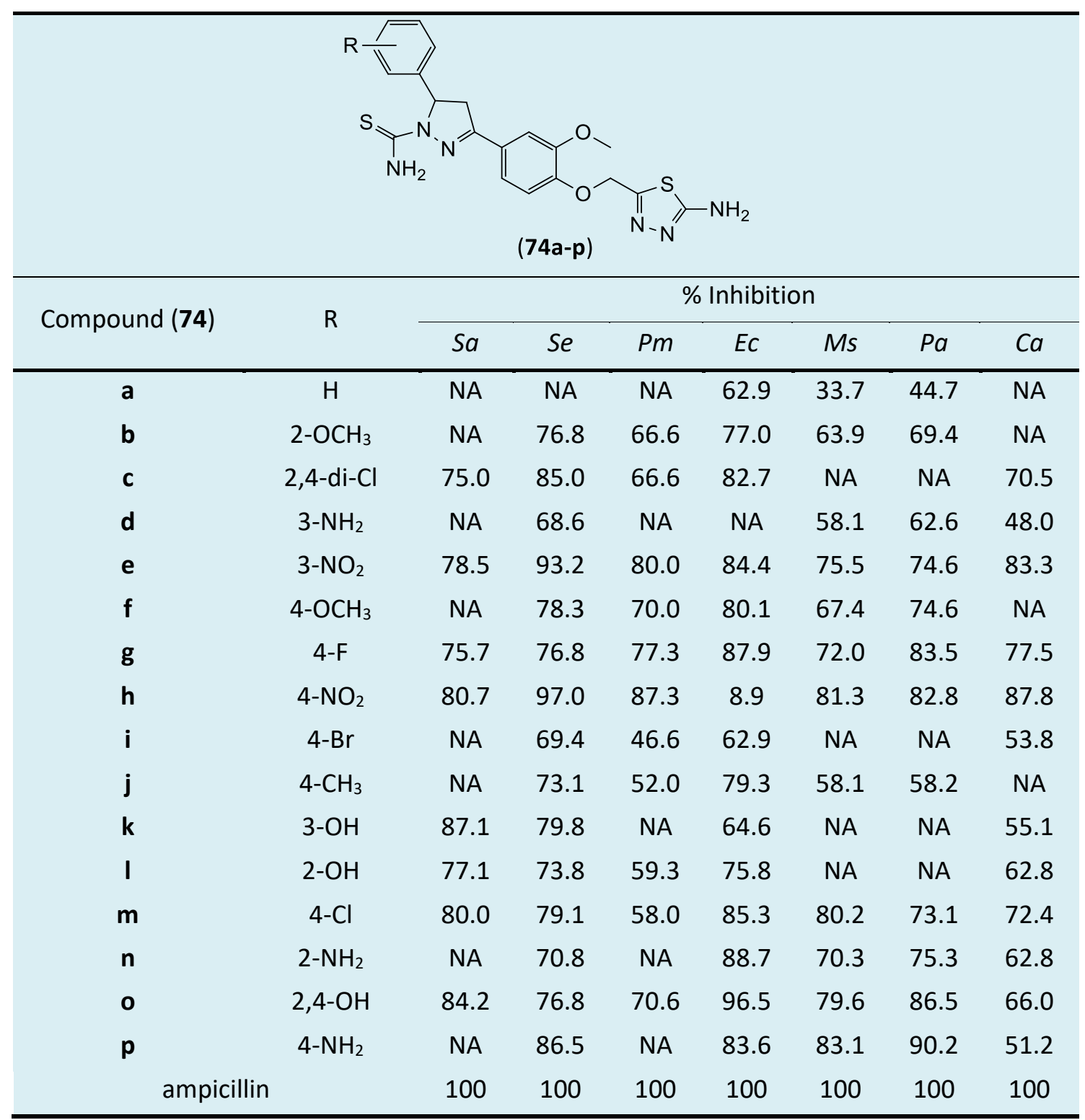

Sa - Staphylococcus aureus; Se - Salmonella enterica; Pm - Proteus mirabilis;

Ec- Escherichia coli V517; Ms - Mycobacterium smegmatis;

$\mathrm{Pa}$ - Pseudomonas aeruginosa;Ca-Candida albicans

Seelam et al. (2016) $)^{81}$ performed microbial studies of 1,3,4-thiadiazoles (102a-k) by the disc diffusion technique and minimum inhibitory concentration (MIC). The minimum inhibitory concentration measurement was determined for compounds that showed significant growth inhibition zones ( $>10 \mathrm{~mm}$ ). The activity of each compound was compared against ofloxacin and miconazole as the standard drugs. The compounds were tested against Bacillus subtilis, Bacillus thuringiensis (Gram positive bacteria), Escherichiacoli and Pseudomonasaeruginosa (Gram negative bacteria). There were also evaluated for their in vitro antifungal potential against Candida glabrata and Candida tropicalis fungal strains. The MIC values are recorded in Table $20{ }^{81}$ 
Table 20. Antimicrobial activity data for compounds (102a-k)

\begin{tabular}{|c|c|c|c|c|c|c|c|}
\hline \multirow{3}{*}{$\begin{array}{l}\text { Compound } \\
\text { (102) }\end{array}$} & \multirow{3}{*}{$\mathrm{R}$} & \multicolumn{6}{|c|}{ Minimum Inhibitory Concentration $(\mu \mathrm{g} / \mathrm{mL})^{\mathrm{a}, \mathrm{b}}$} \\
\hline & & \multicolumn{4}{|c|}{ Antibacterial activity } & \multicolumn{2}{|c|}{ Antifungal activity } \\
\hline & & Bs & $B t$ & Ec & $\mathrm{Pa}$ & $\mathrm{Cg}$ & $C t$ \\
\hline a & $\mathrm{H}$ & 1 & 1 & 0.9 & 1 & 0.5 & 0.5 \\
\hline b & $2-\mathrm{Ph}$ & 1 & 1 & 0.9 & 1 & 0.3 & 0.1 \\
\hline c & $3-\mathrm{NO}_{2}$ & 0.2 & $>0.2$ & 0.1 & 0.5 & 0.5 & 0.5 \\
\hline d & $2-\mathrm{Cl}$ & $>0.1$ & 0.4 & 0.1 & 0.5 & 0.2 & $>0.2$ \\
\hline e & $3-\mathrm{Cl}$ & $>0.3$ & 0.5 & 0.5 & 0.2 & 1 & $>1$ \\
\hline$f$ & $4-\mathrm{Cl}$ & $>0.2$ & $>0.2$ & 0.3 & 0.5 & $>0.4$ & 0.6 \\
\hline g & $2,3-\mathrm{Cl}$ & 0.2 & 0.2 & 0.1 & 0.4 & 0.9 & $>1$ \\
\hline h & $4-\mathrm{CH}_{3}$ & 0.8 & 0.5 & 0.5 & 1 & $>0.1$ & 0.2 \\
\hline $\mathbf{i}$ & $4-\mathrm{OCH}_{3}$ & 1 & 0.8 & $>1$ & 0.5 & $>0.1$ & 0.2 \\
\hline j & $4-\mathrm{NO}_{2}$ & 0.2 & 0.7 & 0.4 & 0.5 & 0.5 & 0.5 \\
\hline k & 4-Cl-ph & 0.2 & 0.3 & $>0.1$ & $>0.4$ & 0.5 & 0.5 \\
\hline \multicolumn{2}{|c|}{ Ofloxacin } & 0.1 & 0.1 & 0.1 & 0.1 & NT & NT \\
\hline \multicolumn{2}{|c|}{ Miconazole } & NT & NT & NT & NT & 0.1 & 0.1 \\
\hline
\end{tabular}

${ }^{a} B s-B$. subtilis; $B t-B$. thuringiensis; $E c-E$. coli; $P a-P$. aeruginosa;

$C g-C$. glabrata; $C t-C$. tropicalis; ${ }^{b} \mathrm{NT}=$ not tested

In general, most of the tested compounds revealed better activity against Gram-positive than Gram-negative bacteria. The antibacterial screening data showed moderate to good activity of the test compounds. Among the screened compounds, 102c, 102d, 102f, 102g and 102k showed a high degree activity against all the bacteria tested. The activities of these compounds were close to standard reference drugs used.

On the other hand, the antifungal screening data showed moderate activity of the test compounds, among which the screened 102b, 102h and 102i showed a high degree of activity against all the microorganisms tested. The activities of these compounds were close to standard reference drugs. ${ }^{81}$

Radwan et al. (2017) synthesized a new series of 1,3,4-thiadiazole derivatives, which presented different groups (aryl, alkyl, allyl) as substituents and evaluated the antifungal property against Candida albicans (Table 21). The authors inserted these substituents at the C-2 position of the thiadiazole ring in order to enhance the lipophilicity and subsequently the biological activity of the compounds. ${ }^{82}$ 
Table 21. Anti-Candida albicans activity of compounds (103a-g)

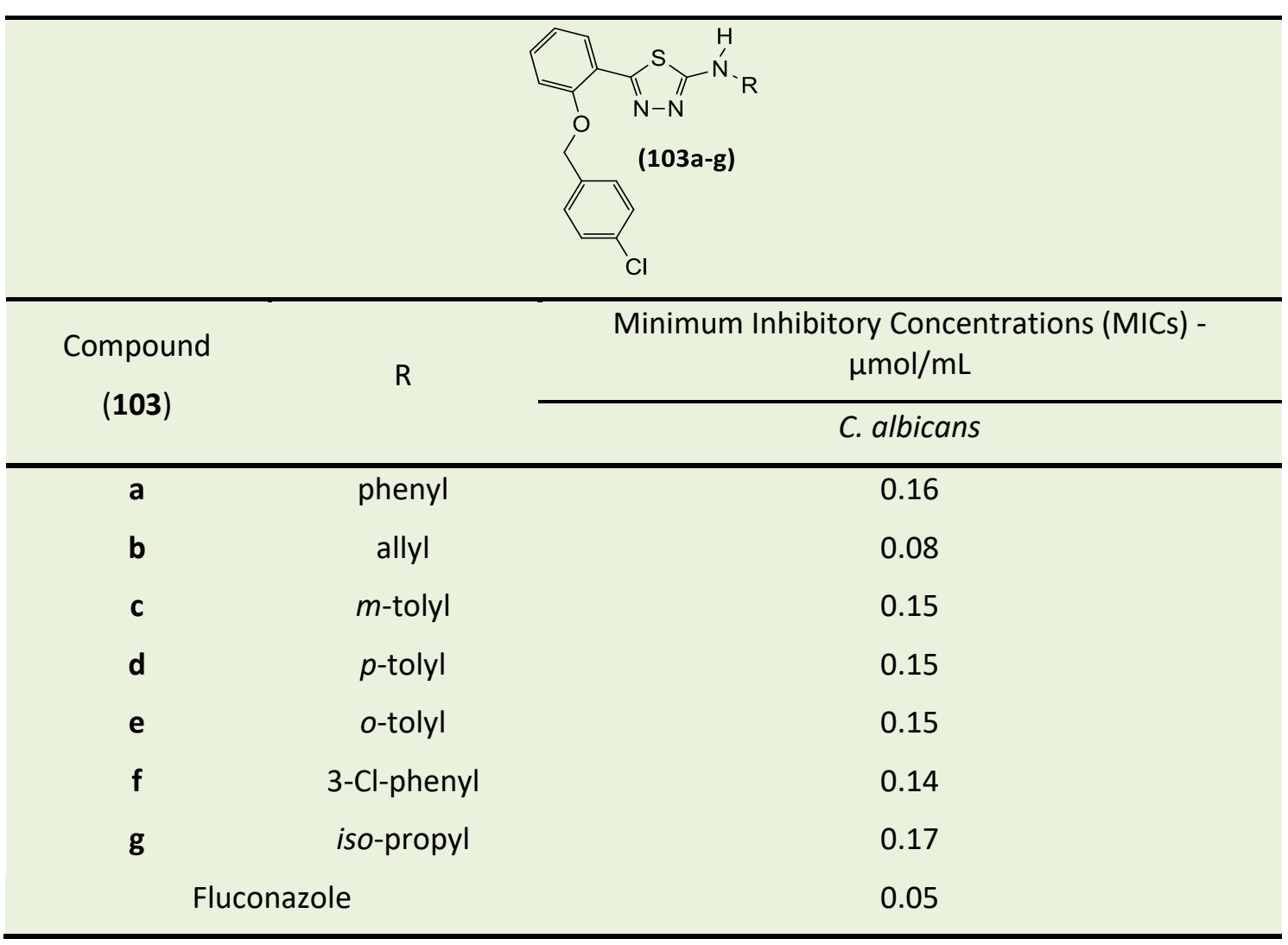

The compounds (103a-g) had MIC values in the range of 0.08 to $0.17 \mu \mathrm{mol} / \mathrm{mL}$ and showed variable and promising anti-Candida albicans activity. The compound $103 \mathrm{~b}$ was found to be the most active, with a MIC value of $0.08 \mu \mathrm{mol} / \mathrm{mL}$.

According to the author, the allyl substituent at position 2 of the heterocyclic ring showed higher activity than the other substituents. Basically, the small size of the allyl group is thought to be related to the high activity of the compound. For optimization of antifungal activity and in view of the results, the author suggests that further studies be undertaken starting with the compound 103b. ${ }^{82}$

Upadhyay and Mishra (2017) ${ }^{22}$ performed microbial studies of 1,3,4-thiadiazoles (104ah) by the disc diffusion technique and minimum inhibitory concentration (MIC). The compounds were tested against Gramnegative bacteria, Escherichia coli, Bacillus subtilis and Pseudomonas aeruginosa, Grampositive bacterium, Staphylococcus aureus and the fungi Aspergillus niger and Candida albicans. Ciprofloxacin and fluconazole were used as standards for antibacterial and antifungal studies and the results are summarized in Tables 22 and 23. ${ }^{22}$ 
Table 22. Data for antimicrobial activity of compounds (104a-h)

\begin{tabular}{|c|c|c|c|c|c|c|c|}
\hline \multirow{4}{*}{$\begin{array}{l}\text { Compound } \\
\text { (104) }\end{array}$} & \multicolumn{2}{|c|}{ 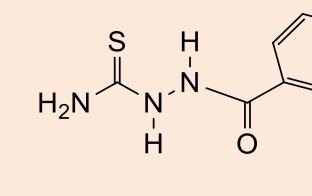 } & \multicolumn{3}{|c|}{$\stackrel{\mathrm{H}_{2} \mathrm{SO}_{4}}{\longrightarrow}$} & & \\
\hline & \multirow{3}{*}{$\mathrm{R}$} & \multicolumn{6}{|c|}{ \% inhibition } \\
\hline & & \multicolumn{4}{|c|}{ Antibacterial activity } & \multicolumn{2}{|c|}{ Antifungal activity } \\
\hline & & $\begin{array}{c}\text { S. } \\
\text { aureus }\end{array}$ & $\begin{array}{c}B . \\
\text { substilis }\end{array}$ & E. coli & $\begin{array}{c}P . \\
\text { aeruginosa }\end{array}$ & $\begin{array}{c}A . \\
\text { niger }\end{array}$ & $\begin{array}{c}\text { C. } \\
\text { albicans }\end{array}$ \\
\hline$a$ & $\mathrm{~F}$ & 90.9 & 85.4 & 79.1 & 70.5 & 51.1 & 51.2 \\
\hline b & $\mathrm{Cl}$ & 85.1 & 81.5 & 75.4 & 67.2 & 43.6 & 49.6 \\
\hline c & $\mathrm{Br}$ & 70.3 & 71.5 & 66.4 & 59.9 & 51.9 & 49.6 \\
\hline d & 1 & 62.8 & 63.8 & 52.3 & 54.1 & 44.3 & 46.3 \\
\hline e & $\mathrm{CH}_{3}$ & 45.5 & 44.6 & 41.8 & 45.9 & 52.6 & 56.1 \\
\hline f & $\mathrm{OH}$ & 57.0 & 54.6 & 60.5 & 58.2 & 58.6 & 65.9 \\
\hline g & $\mathrm{OCH}_{3}$ & 56.2 & 53.1 & 47.0 & 53.3 & 57.9 & 65.0 \\
\hline h & $\mathrm{OC}_{2} \mathrm{H}_{5}$ & 64.5 & 63.1 & 53,7 & 46.7 & 57.1 & 61.8 \\
\hline \multicolumn{2}{|c|}{ Ciprofloxacin $^{a}$} & 100 & 100 & 100 & 100 & NT & NT \\
\hline \multicolumn{2}{|c|}{ Fluconazole ${ }^{a}$} & NT & NT & NT & NT & 100 & 100 \\
\hline
\end{tabular}

${ }^{\mathrm{a} C o n c e n t r a t i o n}-20 \mu \mathrm{g} / \mathrm{mL} ; \mathrm{NT}=$ not tested

Results presented in Table 22 showed that 104a and 104b presented a high degree of activity against Staphylococcus aureus and Bacillus substilis (inhibition between $80 \%$ and $91 \%)$, which are close to the standard drugs. The compounds 104a, 104b, 104c and 104f showed moderate antibacterial activity when compared to ciprofloxacin against Escherichia coli and Pseudomonas aeruginosa $(59 \%$ to $80 \%$ ). Compounds 104e and 104g exhibited mild inhibitory activity. ${ }^{22}$

The study showed that 104a (4fluorophenyl on C-5 of thiadiazole nucleus) produced the highest antimicrobial activity against all bacterial strains while (104b-c) showed significant antibacterial activity. ${ }^{22}$
In contrast, $104 \mathrm{f}(\mathrm{R}=4$-hydroxy) and $104 \mathrm{~g}$ $(R=4$-methoxy) showed better fungal activities when compared to results against bacteria. The antibacterial activities of compounds 104e $(R=$ methyl) and 104g $(R=$ methoxy) were the lowest. ${ }^{22}$

Some of the compounds in the series were moderated in their action against Aspergillus niger and Candida albicans. Compounds (104f-h) showed better inhibitory action (57\% to $66 \%$ inhibition), while the other compounds showed mild antifungal activities (Table 22). ${ }^{22}$ Table 23 shows the MIC values for the most potent compounds. 
Table 23. Minimum inhibitory concentrations of the compounds with the higher percentages of inhibition reported by Upadhyay and Mishra ${ }^{22}$

\begin{tabular}{|c|c|c|c|c|c|c|c|}
\hline \multirow{3}{*}{$\begin{array}{l}\text { Compound } \\
\text { (104) }\end{array}$} & \multirow{3}{*}{$\mathrm{R}$} & \multicolumn{6}{|c|}{ Minimum Inhibitory Concentrations (MICs) - $\mu \mathrm{g} / \mathrm{mL}$} \\
\hline & & \multicolumn{4}{|c|}{ Antibacterial activity } & \multicolumn{2}{|c|}{ Antifungal activity } \\
\hline & & $\begin{array}{c}\text { S. } \\
\text { aureus }\end{array}$ & B. substilis & E. coli & $\begin{array}{c}P . \\
\text { aeruginosa }\end{array}$ & A. niger & $\begin{array}{c}C . \\
\text { albicans }\end{array}$ \\
\hline a & $\mathrm{F}$ & 20 & 22 & 24 & 32 & 44 & 48 \\
\hline b & $\mathrm{Cl}$ & 28 & 26 & 30 & 36 & NT & NT \\
\hline c & $\mathrm{Br}$ & 34 & 36 & 38 & 38 & NT & NT \\
\hline f & $\mathrm{OH}$ & 36 & 38 & 40 & 40 & 34 & 32 \\
\hline g & $\mathrm{OCH}_{3}$ & NT & NT & NT & NT & 42 & 36 \\
\hline \multicolumn{2}{|c|}{ Ciprofloxacin } & 18 & 20 & 20 & 24 & NT & NT \\
\hline \multicolumn{2}{|c|}{ Fluconazole } & NT & NT & NT & NT & 26 & 24 \\
\hline
\end{tabular}

NT = not tested

Based on the results of antimicrobial activity in vitro and analysis of structure, the author suggests that substitution on $\mathrm{C}-4$ of the aromatic ring linked at the $\mathrm{C}-5$ position of the thiadiazole nucleus determines the antibacterial and antifungal activities. The electron withdrawing group $(\mathrm{F}, \mathrm{Cl}$ and $\mathrm{Br})$ at para position of the aromatic ring is necessary for the potency of such antibacterial agents. ${ }^{22}$

Gür et al. (2017) performed microbial studies of 1,3,4-thiadiazoles (105a-d) using in vitro antibacterial and antifungal activity tests against nine different bacteria (Salmonella enteritidis, Salmonella typhimurium,
Salmonella infantis, Salmonella Kentucky, Staphylococcus aureus, Enterobacter aerogenes, Bacillus subtilis, Escherichia coli and Enterococcus durans) and one fungus (Candida albicans) using the disk diffusion method. ${ }^{83}$ Here the synthesized 1,3,4thiadiazole derivatives exhibited effective antimicrobial activity against S. aureus, E. coli, and $C$. albicans. According to the author, the 1,3,4-thiadiazole derivatives can be considered as a source of bioactive agents for pharmacological and medicinal applications. The antimicrobial activity test results are shown in Table $24 .{ }^{83}$ 
Barbosa, G. A. D.; de Aguiar, A. P.

Table 24. Antimicrobial activity results for the compounds (105a-d)

\begin{tabular}{|c|c|c|c|c|c|}
\hline & & & $\begin{array}{l}\prod_{-N}^{H_{1}^{\prime}}{ }^{N_{1}} \cdot R \\
05 a-d)\end{array}$ & & \\
\hline \multirow{3}{*}{$\begin{array}{l}\text { Compound } \\
\text { (105) }\end{array}$} & \multirow{3}{*}{$\mathrm{R}$} & \multirow{3}{*}{$\mu \mathrm{L}$} & \multicolumn{3}{|c|}{ Diameter of zone of inhibition $(\mathrm{mm})$} \\
\hline & & & \multicolumn{2}{|c|}{ Antibacterial activity } & \multirow{2}{*}{$\begin{array}{c}\text { Antifungal activity } \\
\text { C.albicans }\end{array}$} \\
\hline & & & S.aureus & E. coli & \\
\hline \multirow{3}{*}{ a } & \multirow{3}{*}{ 2- $\mathrm{CH}_{3}$-phenyl } & 30 & NA & NA & NA \\
\hline & & 50 & 13 & NA & NA \\
\hline & & 80 & 13 & NA & NA \\
\hline \multirow{3}{*}{ b } & \multirow{3}{*}{ 4-F-phenyl } & 30 & NA & NA & NA \\
\hline & & 50 & 9 & NA & 13 \\
\hline & & 80 & 13 & NA & 14 \\
\hline \multirow{3}{*}{ c } & \multirow{3}{*}{ benzyl } & 30 & 8 & NA & 14 \\
\hline & & 50 & 12 & NA & 16 \\
\hline & & 80 & 13 & NA & 19 \\
\hline \multirow{3}{*}{ d } & \multirow{3}{*}{ methyl } & 30 & 12 & 15 & 12 \\
\hline & & 50 & 15 & 15 & 13 \\
\hline & & 80 & 17 & 15 & 15 \\
\hline
\end{tabular}

NA = no activity

In Xie et al. (2017), evaluated antimicrobial activities of four novel 5-methyl-1,3,4thiadiazole-2-thiol-substituted by a group derived from $\mathrm{N}, \mathrm{N}$-bis(2-hydroxyethyl) quaternary ammonium salts (QAS) (Figure 6). The compound $106 \mathrm{~d}$ displayed a potent antimicrobial effect against different common pathogens (Staphylococcus aureus, Escherichia coli, Pseudomonas. aeruginosa, Proteus vulgaris, Candida albicans, Physalospora piricola, Aspergillus niger) and had relatively low cytotoxity against two human cell lines (HaCat and LO2), according to Table 25. ${ }^{84}$

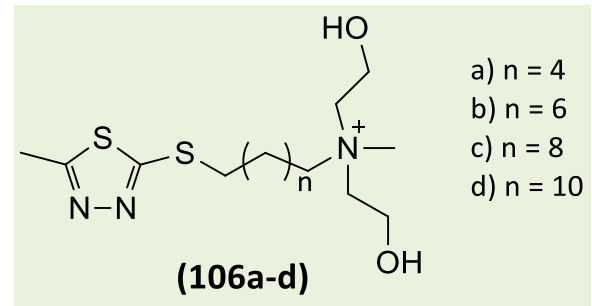

Figure 6. Quaternary ammonium salts with antimicrobial activity 
Table 25. Minimal inhibitory concentration of thiazole containing quaternary ammonium salts

\begin{tabular}{|c|c|c|c|c|c|c|c|}
\hline \multirow{3}{*}{$\begin{array}{l}\text { Compound } \\
\text { (106) }\end{array}$} & \multicolumn{7}{|c|}{ Minimum Inhibitory Concentrations (MICs) - $\mu \mathrm{g} / \mathrm{mL}$} \\
\hline & \multicolumn{4}{|c|}{ Antibacterial activity } & \multicolumn{3}{|c|}{ Antifungal activity } \\
\hline & $\begin{array}{c}\text { S. } \\
\text { aureus }\end{array}$ & E. coli & $\begin{array}{c}P . \\
\text { aeruginosa }\end{array}$ & $\begin{array}{c}P . \\
\text { vulgaris }\end{array}$ & $\begin{array}{c}\text { C. } \\
\text { albicans }\end{array}$ & $\begin{array}{c}P . \\
\text { piricola }\end{array}$ & $\begin{array}{c}\text { A. } \\
\text { niger }\end{array}$ \\
\hline a & 100 & 100 & 200 & 100 & 50 & 25 & 50 \\
\hline b & 50 & 50 & 100 & 50 & 25 & 12.5 & 25 \\
\hline c & 25 & 50 & 50 & 50 & 25 & 12.5 & 12.5 \\
\hline d & 12.5 & 25 & 50 & 25 & 12.5 & 6.25 & 12.5 \\
\hline
\end{tabular}

In this study, the cytotoxicity of target compounds was evaluated for human epidermal (HaCat) and human normal liver (LO2) cell lines using the MTT assay (Table 26). The $\mathrm{IC}_{50}$ values of $106 \mathrm{a}-\mathrm{b}$ were more than $50 \mathrm{mg} / \mathrm{mL}$ for $\mathrm{LO} 2$ and HaCat. In addition, compounds $106 \mathrm{c}-\mathrm{d}$ also showed low $\mathrm{IC}_{50}$ values (more than $25 \mathrm{mg} / \mathrm{mL}$ ). These data demonstrated that 106a-b were non-toxic for LO2 and HaCat. Specifically, the lower-toxic compounds $106 \mathrm{c}$ and $106 \mathrm{~d}$ with better activities than the others might become superior antimicrobial agents. ${ }^{84}$

Table 26. Cytotoxicity of QASs

\begin{tabular}{ccc}
\hline \multirow{2}{*}{$\begin{array}{c}\text { Compound } \\
(\mathbf{1 0 6})\end{array}$} & $\mathrm{I} \mathrm{C}_{50}(\mu \mathrm{gg} / \mathrm{mL})$ \\
\cline { 2 - 3 } & $>100$ & HaCat \\
\hline a & $86.52 \pm 5.33$ & $>100$ \\
b & $43.18 \pm 2.67$ & $65.38 \pm 3.12$ \\
c & $30.12 \pm 2.32$ & $36.87 \pm 2.81$ \\
d & & $27.03 \pm 2.53$ \\
\hline
\end{tabular}

El-Badry et al. (2018) synthesized a novel series of 1,3,4-thiadiazolyl-sulfanyl-4,5dihydropyridazin-3(2H)-ones and evaluated the antimicrobial activity against two Grampositive bacteria (Streptococcus pneumonia and Bacillus subtilis), two Gram-negative bacteria

(Escherichia coli, Pseudomonas aeruginosa), and four fungi (Aspergillus fumigatus, Syncephalastrumracemosum, Geotrichum candidum and Candida albicans) (Figure 7). ${ }^{27}$ 
Barbosa, G. A. D.; de Aguiar, A. P.

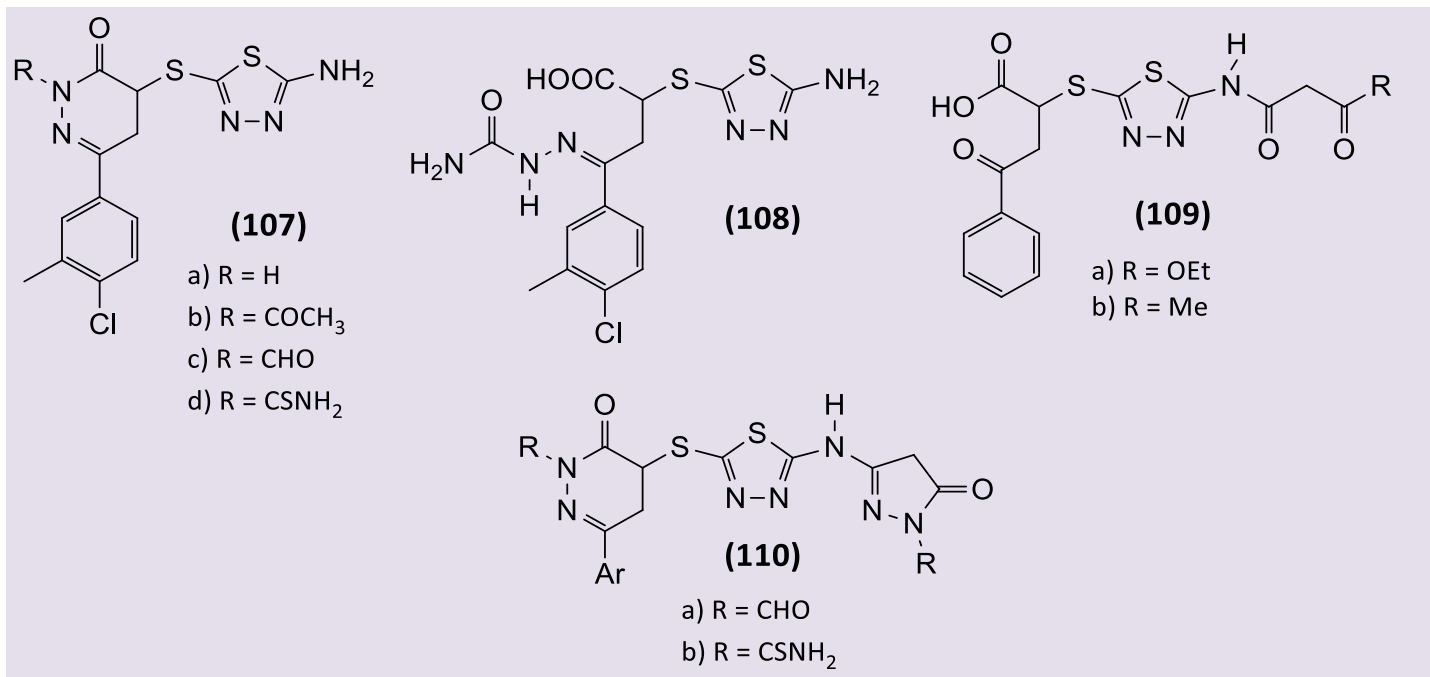

Figure 7. Novel series of 1,3,4-thiadiazolyl-sulfanyl-4,5-dihydropyridazin-3(2H)-ones

Ampicillin, gentamicin and amphotericin B were used as control drug standards for Grampositive bacteria, Gram-negative bacteria, and fungi references respectively. The inhibition zones $(\mathrm{mm})$ of the compounds are given below (Table 27).

Table 27. Antimicrobial activities of novel series of 1,3,4-thiadiazoles synthesized by El-Badry et $a l^{27}$

\begin{tabular}{ccccccccc}
\hline & \multicolumn{6}{c}{ Zone of inhibition (mm) $-5 \mathrm{mg} / \mathrm{mL}^{\mathrm{a}, \mathrm{b}}$} \\
\cline { 2 - 9 } Compound & \multicolumn{7}{c}{ Antibacterial activity } & \multicolumn{5}{c}{ Antifungal activity } \\
\cline { 2 - 9 } & $S p$ & $B s$ & $E c$ & $P a$ & $A f$ & $S r$ & $G c$ & $C a$ \\
\hline 107a & 21.7 & 23.2 & 20.8 & NA & 22.6 & 26.7 & 23.3 & NA \\
107b & 19.4 & 21.2 & 18.6 & NA & 20.3 & 19.2 & 20.7 & NA \\
107c & 17.9 & 18.2 & 17.7 & NA & 18.2 & 17.6 & 18.9 & NA \\
107d & 29.4 & 34.6 & 27.2 & NA & 26.4 & 27.3 & 31.2 & 22.4 \\
108 & 24.6 & 28.6 & 23.2 & NA & 22.8 & 21.8 & 24.2 & 17.3 \\
109a & 16.0 & 18.3 & 13.0 & NA & 10.6 & 11.7 & 16.5 & NA \\
109b & 13.6 & 15.6 & 10.3 & NA & NA & NA & NA & NA \\
110a & 22.5 & 24.2 & 19.3 & NA & 19.6 & 20.4 & 23.6 & NA \\
110b & 25.1 & 27.4 & 23.4 & NA & 22.3 & 23.4 & 27.3 & NA \\
Ampicillin & 23.8 & 32.4 & NT & NT & NT & NT & NT & NT \\
Gentamicin & NT & NT & 19.9 & 19.9 & NT & NT & NT & NT \\
Amphotericin B & NT & NT & NT & NT & 23.7 & 19.7 & 28.7 & 25.4 \\
\hline
\end{tabular}

${ }^{a} S p$-Streptococcus pneumonia; Bs-Bacillus subtilis; Ec- Escherichia coli;

$\mathrm{Pa}$-Pseudomonas aeruginosa; Af-Aspergillus fumigatus; Sr-Syncephalastrum racemosum;

Gc- , Geotrichum candidum; Ca - Candida albicans; ${ }^{b} \mathrm{NA}=$ no activity; NT = not tested 
Compounds 107d, 108 and $110 d$ showed potent activity against $B$. subtilis and their effect exceeded the control drug against $S$. pneumonia and $E$. coli. In addition, the compounds 107b, 107c, and 110a demonstrated potent activity, while 109a and $109 \mathrm{~b}$ were the least active against all strains. All compounds were inactive against $P$. aeruginosa. ${ }^{27}$
Compound 107d was the most potent against all the fungi and its effect exceeded the control drug. Compounds $107 \mathrm{~b}-\mathrm{c}$ only revealed moderate activities against $G$. candidum, while 107a, 108, 110a, and 110b were more potent. Against $C$. albicans strain, the compound $107 \mathrm{~d}$ was the most potent while 108 was the least effective. ${ }^{27}$ Table 28 shows the MIC values for the most potent compounds. ${ }^{27}$

Table 28. Antibacterial and antifungal minimum inhibition concentration for the most potent thiadiazoles reported by El-Badry et $a^{27}$

\begin{tabular}{|c|c|c|c|c|c|c|}
\hline \multirow{3}{*}{ Compounds } & \multicolumn{6}{|c|}{ Minimum Inhibitory Concentrations (MICs) - $\mathrm{mg} / \mathrm{mL}$} \\
\hline & \multicolumn{3}{|c|}{ Antibacterial activity } & \multicolumn{3}{|c|}{ Antifungal activity } \\
\hline & $\begin{array}{c}\text { S. } \\
\text { pneumonia }\end{array}$ & $\begin{array}{c}\text { B. } \\
\text { substilis }\end{array}$ & E. coli & $\begin{array}{c}A . \\
\text { fumigatus }\end{array}$ & $\begin{array}{c}S . \\
\text { racemosum }\end{array}$ & $\begin{array}{c}G . \\
\text { candidum }\end{array}$ \\
\hline 107d & 0.60 & 1.25 & 0.60 & 1.25 & 1.25 & 1.25 \\
\hline $109 a$ & 2.50 & 1.25 & 1.25 & 5.00 & 2.50 & 5.00 \\
\hline $109 b$ & 2.50 & 2.50 & 2.50 & NT & NT & NT \\
\hline $110 \mathrm{~b}$ & 0.60 & 0.60 & 0.60 & 2.50 & 1.25 & 2.50 \\
\hline Ampicillin & 0.60 & 0.60 & NT & NT & NT & NT \\
\hline Gentamicin & NT & NT & 0.60 & NT & NT & NT \\
\hline Amphotericin B & NT & NT & NT & 0.60 & 0.60 & 0.60 \\
\hline
\end{tabular}

NT = not tested

Padmaja et al. (2018) performed microbial studies of 1,3,4-thiadiazoles (111a-f) by applying in vitro antibacterial (Gram-positive and Gram-negative) activity tests against four different bacteria (Staphylococcus aureus, Bacillus subtilis, Klebsiella peneumoniae and Pseudomonas aeruginosa) using the disk diffusion method in four different concentrations 12.5, 25, 50 and $100 \mu \mathrm{g} /$ well (Table 29). ${ }^{85}$

According to the report, the results (Table 29) indicated that the tested compounds were more susceptible towards the Gram-negative bacteria than the Gram-positive ones. The compounds with chloro substituents showed slightly higher activity. In fact, 111c and 111f were particularly effective against $P$. aeruginosa in all the tested concentrations. ${ }^{85}$

The presence of chloro and nitro as substituents on the phenyl ring provides greater activity than the methyl and methoxy substituents. This may be due to the presence of more electronegative atoms, which may increase the biological potency, bioavailability, metabolic stability and lipophilicity. ${ }^{85}$ 
Table 29. Antibacterial activity of compounds (111a-f) using the diffusion method

\begin{tabular}{|c|c|c|c|c|c|c|}
\hline \multirow{3}{*}{$\begin{array}{l}\text { Compound } \\
\text { (111) }\end{array}$} & \multirow{3}{*}{$\mathrm{R}$} & \multirow{3}{*}{$\mu \mathrm{g} /$ well } & \multicolumn{4}{|c|}{ Diameter of zone of inhibition (mm) } \\
\hline & & & \multicolumn{2}{|c|}{ Gram-positive } & \multicolumn{2}{|c|}{ Gram-negative } \\
\hline & & & S.aureus & B.subtilis & $\begin{array}{c}P . \\
\text { aeruginosa }\end{array}$ & $\begin{array}{c}K . \\
\text { pneumoniae }\end{array}$ \\
\hline \multirow{4}{*}{ a } & \multirow{4}{*}{ H } & 12.5 & 10 & 11 & 15 & 20 \\
\hline & & 25 & 11 & 13 & 19 & 21 \\
\hline & & 50 & 12 & 15 & 20 & 23 \\
\hline & & 100 & 13 & 18 & 24 & 26 \\
\hline \multirow{4}{*}{ b } & \multirow{4}{*}{$4-\mathrm{CH}_{3}$} & 12.5 & NA & 8 & 10 & 14 \\
\hline & & 25 & NA & 10 & 12 & 16 \\
\hline & & 50 & NA & 11 & 15 & 18 \\
\hline & & 100 & 8 & 13 & 19 & 20 \\
\hline \multirow{4}{*}{ c } & \multirow{4}{*}{$4-\mathrm{Cl}$} & 12.5 & 15 & 21 & 26 & 28 \\
\hline & & 25 & 17 & 23 & 29 & 30 \\
\hline & & 50 & 19 & 26 & 32 & 32 \\
\hline & & 100 & 21 & 29 & 34 & 35 \\
\hline \multirow{4}{*}{ d } & \multirow{4}{*}{$4-\mathrm{Br}$} & 12.5 & 11 & 17 & 19 & 24 \\
\hline & & 25 & 13 & 19 & 23 & 26 \\
\hline & & 50 & 15 & 21 & 25 & 28 \\
\hline & & 100 & 17 & 24 & 29 & 31 \\
\hline \multirow{4}{*}{ e } & \multirow{4}{*}{$\begin{array}{c}4- \\
\mathrm{OCH}_{3}\end{array}$} & 12.5 & NA & NA & NA & NA \\
\hline & & 25 & NA & NA & NA & NA \\
\hline & & 50 & NA & NA & 8 & NA \\
\hline & & 100 & NA & NA & 10 & 13 \\
\hline \multirow{4}{*}{$f$} & \multirow{4}{*}{$4-\mathrm{NO}_{2}$} & 12.5 & 16 & 22 & 28 & 31 \\
\hline & & 25 & 18 & 24 & 31 & 33 \\
\hline & & 50 & 20 & 27 & 33 & 35 \\
\hline & & 100 & 23 & 31 & 35 & 38 \\
\hline
\end{tabular}

NT $=$ not tested

Table 30 shows the minimum inhibitory concentration (MIC) and minimum bactericidal concentration $(\mathrm{MBC}$ ) values of the most potent compounds. According to the author, the antimicrobials are usually regarded as bactericidal if the $M B C$ is not greater than four times the MIC. The MBC values for 111c and 111f were twice the MIC values particularly against $P$. aeruginosa. In general, the compounds having electron withdrawing substituents on the phenyl ring displayed higher antimicrobial activity than the compounds with electron donating substituents. ${ }^{85}$ 
Table 30. Antibacterial minimum inhibitory and bactericidal concentration in compounds with better performance

\begin{tabular}{ccccc}
\hline \multirow{2}{*}{$\begin{array}{c}\text { Compound } \\
(111)\end{array}$} & \multicolumn{4}{c}{ Minimum Inhibitory Concentrations - MICs (MBC) } \\
\cline { 2 - 5 } & S.aureus & B.subtilis & P. aeruginosa & K. pneumoniae \\
\cline { 2 - 5 } & $50(200)$ & $25(100)$ & $6.25(12.5)$ & $12.5(50)$ \\
c & $50(200)$ & $25(100)$ & $6.25(12.5)$ & $12.5(50)$ \\
Chloramphenicol & 6.25 & 6.25 & 6.25 & 12.5 \\
\hline
\end{tabular}

$\mathrm{NA}=$ no activity

\section{Conclusion}

The studies reported in this review have shown the significant importance of 1,3,4thiadiazole and its derivatives for the design of new pharmacological compounds and treatment for bacterial infections. Thiadiazoles are a very important class of heterocyclic compounds with diverse pharmacological properties. The therapeutic potential of 1,3,4-thiadiazole is a reality, since it is present in commercial drugs, as well as the focus of different studies with relevant results; mainly for microbiological activities. The possibility of being used as a bioisostere for other heterocycles, such as oxadiazole, provides an increase in lipophilicity without causing a loss of pharmacological properties. In general terms, the synthetic methods for preparation of diverse 1,3,4-thiadiazole derivatives are very effective, allowing the design and preparations of new antibacterial agents.

\section{References}

${ }^{1}$ Parmar, K. C.; Umrigar, N. H. Review article on synthesis of 1,3,4-thiadiazole derivatives and it's biological activity. Journal of Chemical and Pharmaceutical Research 2017, 9, 202. [Link]

${ }^{2}$ Talesara, G. L.; Kumawat, M. Synthesis of ethoxyphthalimido derivatized thiadizole assembled imidazolidinone and chloroazetidinone systems from common intermediate Schiff's bases and evaluation of their antibacterial activity. Journal of Applicable Chemistry 2013, 2, 754. [Link]

${ }^{3}$ Singh, A. K.; Mishra, G.; Jyoti, K. Review on biological activities of 1,3,4-thiadiazole derivatives. Journal of Applied Pharmaceutical Science 2011, 1, 44. [Link]

${ }^{4}$ Mehta, D.; Taya, P. A review on the various biological activities of thiadiazole. International Journal of Pharmacy and Pharmaceutical Sciences 2015, 7, 39. [Link]

${ }^{5}$ Kamal, M.; Shakya, A. K.; Jawaid, T. 1,3,4thiadiazole as antimicrobial agent: A review. International Journal of Biomedical Research 2011, 2, 41. [CrossRef]

${ }^{6}$ Jain, A. K.; Sharma, S.; Vaidya, A.; Ravichandran, V.; Agrawal, R. K.1,3,4thiadiazole and its derivatives: $A$ review on recent progress in biological activities. Chemical Biology \& Drug Design 2013, 81, 557. [CrossRef] [PubMed] 
${ }^{7}$ Zou, X.; Lai, L.; Jin, G.; Zhang, Z.Synthesis, fungicidal activity, and 3D-QSAR of pyridazinone-substituted 1,3,4-oxadiazoles and 1,3,4-thiadiazoles. Journal of Agricultural and Food Chemistry 2002, 50, 3757. [CrossRef] [PubMed]

${ }^{8}$ Altintop, M. D.; Ciftci, H. I.; Radwan, M. O.; Sever, B.; Kaplancikli, Z. A.; Ali, T. F. S.; Koga, R.; Fujita, M.; Otsuka, M.; Özdemir, A. Design, synthesis, and biological evaluation of novel 1,3,4-thiadiazole derivatives as potential antitumor agents against chronic myelogenous leukemia: Striking effect of nitrothiazole moiety. Molecules 2018, 23, 59. [CrossRef] [PubMed]

${ }^{9}$ Srivastava, S.; Prasad, R. K.; Saini, R. Thiadiazole: A brief review. World Journal of Pharmacy and Pharmaceutical Sciences 2014, 3, 1198. [Link]

${ }^{10}$ Pandit, N.; Shah, K.; Agrawal, N.; Upmanyu, N.; Shrivastava, S. K.; Mishra, P.Synthesis, characterization and biological evaluation of some novel fluoroquinolones. Medicinal Chemistry Research 2016, 25, 843. [CrossRef]

${ }^{11}$ Kumar, K. R.; Rani, B. L. Synthesis, characterization and biological evaluation of [2-(substituted aryl)-3-[5-(substituted phenyl)-1,3,4-thiadiazole]-4-oxothiazolidines. European Journal Biomedical and Pharmaceutical Sciences 2016, 3, 288. [Link]

${ }^{12}$ Manimaran, T.; Anand, R. M.; Jishala, M.; Gopalasatheeskumar, K.; Parthiban, S.; Boopathi, T. Synthesis and characterization of substituted 1,3,4 thiadiazole as potential antimicrobial agents. International Journal of Pharmaceutical, Chemical and Biological Sciences 2017, 7, 142. [Link]

${ }^{13}$ Zender, M.; Klein, T.; Henn, C.; Kirsch, B.; Maurer, C. K.; Kail, D.; Ritter, C.; Dolezal, O.; Steinbach, A.; Hartmann, R. W. Discovery and biophysical characterization of 2-aminooxadiazoles as novel antagonists of PqsR, an important regulator of Pseudomonas aeruginosa virulence. Journal Medicinal Chemistry 2013, 56, 6761. [CrossRef] [PubMed]

${ }^{14}$ Padmavathi, V.; Swapna, M.; Premakumari, C.; Reddy, S. N.; Padmaja, A. Synthesis and antioxidant activity of a variety of sulfonamidomethane linked 1,3,4-oxadiazoles and thiadiazoles. Chemical and Pharmaceutical Bulletin 2013, 61, 611. [CrossRef]

${ }^{15}$ Li, P.; Shi, L.; Gao, M.; Yang, X.; Xue, W.; Jin, L.; Hu, D.; Song, B.Antibacterial activities against rice bacterial leaf blight and tomato bacterial wilt of 2-mercapto-5-substituted1,3,4-oxadiazole/thiadiazole derivatives. Bioorganic \& Medicinal Chemistry Letters 2015, 25, 481. [CrossRef] [PubMed]

${ }^{16}$ Mullick, P.; Khan, S. A; Verma, S.; Alam, O.Synthesis, characterization and antimicrobial activity of new thiadiazole derivatives. Bulletin of the Korean Chemical Society 2010, 31, 2345. [CrossRef]

${ }^{17}$ Zhu, H.; Hu, Y.; Li, C.; Wang, X. W.; Yang, Y. 1,3,4-Thiadiazole: Synthesis, reactions, and applications in medicinal, agricultural, and materials chemistry. Chemical Reviews 2014, 114, 5572. [CrossRef] [PubMed]

${ }^{18}$ Hamama, W. S.; Raoof, H. A.; Zoorob, H. H.; Ibrahim, M. E. Synthesis of some new binary and spiro heterocyclic thiazolo[4,3b] $[1,3,4]$ thiadiazole ring systems and their antimicrobial evaluation. Der Pharma Chemica 2017, 9, 28. [Link]

${ }^{19}$ Chauviere, G.; Bouteille, B.; Enanga, B.; Albuquerque, C.; Croft, S. L.; Dumas, M.; Périé, J. Synthesis and biological activity of nitro heterocycles analogous to megazol, a Trypanocidal lead. Journal of Medicinal Chemistry 2003, 46, 427. [CrossRef] [PubMed]

${ }^{20}$ Alam, F.; Dey, B. K.Synthesis, characterization and in vitroanti-oxidant activity of some novel 1,3,4-thiadiazole derivatives. Der Pharma Chemica 2015, 7, 230. [Link]

${ }^{21}$ Pandey, A.; Dewangan, D.; Verma, S.; Mishra, A.; Dubey, R. D.Synthesis of Schiff bases of 2-amino-5-aryl-1,3,4-thiadiazole and its analgesic, anti-inflammatory, anti-bacterial and anti-tubercular activity.International Journal of ChemTech Research 2011, 3, 178. [Link]

${ }^{22}$ Mishra, P.; Upadhyay, P.K. Synthesis, antimicrobial and anticancer activities of 5-(4- 
substituted-phenyl)-1,3,4-thiadiazole-2amines. Rasayan Journal of Chemistry 2017, 10, 254. [CrossRef]

23 Jatav, V.; Mishra, P.; Kashaw, S.; Stables, J. $P$. Synthesis and CNS depressant activity of some novel 3-[5-substituted 1,3,4-thiadiazole2-yl]-2-styryl quinazoline-4(3H)onesEuropean Journal of Medicinal Chemistry 2008, 43, 135. [CrossRef] [PubMed]

${ }^{24}$ Chhajed, M.; Shrivastava, A. K.; Taile, V.Design and syntheses of some new 5[Benzenesulphonamido]-1,3,4-thiadiazol-2sulphonamide as potent antiepileptic agent. Macroheterocycles 2013, 6, 199. [CrossRef]

25 De Souza, M. V. N.; Moreth, M.; Ornelas, D.; Gomes, C. R. B.Nitroimidazóis - uma promissora classe de substâncias para o tratamento da Tuberculose. Revista Virtual de Química 2010, 2, 105. [CrossRef]

${ }^{26}$ Serban, G.; Stanasel, O.; Serban, E.; Bota, S. 2-Amino-1,3,4-thiadiazole as a potential scaffold for promising antimicrobial agents. Drug Design, Development and Therapy 2018, 12, 1545. [CrossRef] [PubMed]

27 EL-Badry, Y. A.; Sallam, M. S.; El-Hashash, M. A. Efficient 1,3,4-thiadiazole-4,5dihydropyridazin-3(2H)-ones as antimicrobial agents. Chemical and Pharmaceutical Bulletin 2018, 66, 427. [CrossRef] [PubMed]

${ }^{28}$ Young, G.; Eyre, W. Oxidation of benzalthiosemicarbazone. Journal of Chemical Society 1901, 79, 54. [CrossRef]

${ }^{29}$ Losanitch, S. M. Decomposition of dithiocarbazinates. Journal of Chemical Society 1922, 121,2542. [CrossRef]

30 Hoggarth, E. Compound related to thiosemicarbzide. Part II. 1benzoylthiosemicarbzides. Journal of Chemical Society 1949, 1163. [CrossRef]

${ }^{31}$ Linganna, N.; Rai, K. M. Transformation of 1,3,4-oxadiazoles to 1,3,4-thiadiazoles using thiourea. Synthetic Communications 1998, 28, 4611. [CrossRef]

32 Hassan, A. A.; El-Shaieb, K. M.; Shaker, R. M.; Dopp, D.New access to pyrazole, oxa(thia)diazole and oxadiazine derivatives.
Heteroatom Chemistry 2005, 16, 12. [CrossRef]

${ }^{33}$ Mullick, P.; Khan, S. A.; Verma, S.; Alam, O.Thiadiazole derivatives as potential anticonvulsant agents. Bulletin of the Korean Chemical Society 2011, 32, 1011. [CrossRef]

34 Li, P.; Shi, L.; Yang, X.; Yang, L.; Chen, X.; Wu, F. Shi, Q. Xu, W. He, M.; Hu, D.; Song, B.Design, synthesis, and antibacterial activity against rice bacterial leaf blight and leaf streak of 2,5substituted-1,3,4-oxadiazole/thiadiazole sulfone derivative. Bioorganic \& Medicinal Chemistry Letters 2014, 24, 1677. [CrossRef] [PubMed]

${ }^{35}$ Aliabadia, A.; Mohammadi-Farania, A.; Roodabehb, S.; Ahmadia, F.Synthesis and biological evaluation of $\mathrm{N}$-(5-(pyridin-2-yl)1,3,4-thiadiazol-2-yl)benzamide derivatives as lipoxygenase inhibitor with potential anticancer activity. Iranian Journal of Pharmaceutical Research 2017, 16, 165. [PubMed]

${ }^{36}$ Petrow, V.; Stephenson, O.; Thomas, A. J.; Wild, A. M. Preparation and hydrolysis of some derivatives of 1,3,4-thiadizoles. Journal of Chemical Society 1958, 1508. [CrossRef]

${ }^{37}$ Sayed, A.; Zaki, Y.; Aish, E. A convenient route for the synthesis of new thiadiazoles. Turkish Journal of Chemistry 2016, 40, 184. [CrossRef]

38 Padmavathi, V.; Durgamma, S.; Syamaiah, K.; Yamini, G.; Reddy, G. D.; Padmaja, A. Synthesis and antioxidant activity of styryl1,3,4-thiadiazoles, pyrazolyl-1,3,4thiadiazoles and isoxazolyl-1,3,4-thiadiazoles. Indian Journal of Chemistry 2017, 56, 325. [Link]

${ }^{39}$ Zhang, L.; Zhao, J.; Zhang, B.; Lu, T.; Chen, Y. Discovery of $\quad[1,2,4]$ triazolo[3,4b] $[1,3,4]$ thiadiazole derivatives as novel, potent and selective c-met kinase inhibitors: Synthesis, SAR study, and biological activity. European Journal of Medicinal Chemistry 2018, 150, 809. [CrossRef] [PubMed]

${ }^{40}$ Mirzaei, J.; Amini, M.; Pirelahi, H.; Shafiee, A. Convenient Syntheses of 5-[(2-Methyl-5nitro-1H-imidazol-1-yl)methyl]-1,3,4- 
oxadiazole-2(3H)thione and $\mathrm{N}$-Substituted 2amino-5-[(2-methyl-5-nitro-1H-imidazol-1-

yl)methyl]-1,3,4-thiadiazoles. Journal of Heterocyclic Chemistry 2008, 45, 921. [CrossRef]

${ }^{41}$ Matsuno, K.; Masuda, Y.; Uehara, Y.; Sato, H.; Muroya, A.; Takahashi, O.; Yokotagawa, T.; Furuya, T.; Okawara, T.; Otsuka, M.; Ogo, N.; Ashizawa, T.; Oshita, C.; Tai, S.; Ishii, H.; Akiyama, Y.; Asai, A. Identification of a new series of STAT3 inhibitors by virtual screening. ACS Medicinal Chemistry Letters 2010, 1, 371. [CrossRef] [PubMed]

${ }^{42}$ Ghate, M. D.; Manna, K. S.; Barot, K. P. Design, synthesis and antimicrobial activities of some novel 1,3,4-thiadiazole, 1,2,4triazole-5-thione and 1,3-thiazolan-4-one derivatives of benzimidazole. Journal Saudi Chemical Society 2017, 21, S35. [CrossRef]

${ }^{43}$ Aryanasab, F.; Halimehjani, A. Z.; Saidi, M. R. Dithiocarbamate as an efficient intermediate for the synthesis of 2-amino-1,3,4thiadiazoles in water. Tetrahedron Letters 2010, 51, 790. [CrossRef]

${ }^{44}$ Augustine, J. K.; Vairaperumal, V.; Narasimhan, S.; Alagarsamy, P.; Radhakrishnan, A. Propylphosphonic anhydride (T3P): an efficient reagent for the one-pot synthesis of 1,2,4-oxadiazoles, 1,3,4oxadiazoles, and 1,3,4-thiadiazoles. Tetrahedron 2010, 65, 9989. [CrossRef]

${ }^{45}$ Kubota, S.; Koida, Y.; Kosaka, T.; Kirino, O. Studies on the synthesis of 1,3,4thiadiazoline-5-thiones from amidrazones and carbon disulfide. Chemicaland Pharmaceutical Bulletin 1970, 18 1696. [CrossRef]

${ }^{46}$ Gong, Y.; Lee, T. Combinatorial syntheses of five-membered ring heterocycles using carbon disulfide and a solid support. Journal of Combinatorial Chemistry 2010, 12, 393. [CrossRef] [PubMed]

${ }^{47}$ Wang, T.; Miao W.; Wu, S.; Bing, G.; Zhang, X.; Qin, Z.; Yu, H.; Qin, X.; Fang, J. Synthesis, crystal structure, and herbicidal activities of 2cyanoacrylates containing 1,3,4-thiadiazole moieties. Chinese Journal of Chemistry 2011, 29, 959. [CrossRef]
${ }^{48}$ Sayed, A. R.; Al-Omir, M. A.; Youssef, M. M. Synthesis of novel triazoles, tetrazine, thiadiazoles and their biological activities. Molecules 2015, 20, 2591. [CrossRef] [PubMed]

${ }^{49}$ Chubb, F. L.; Nissenbaum, J. Some hypoglycemic thiadiazoles. Canadian Journal of Chemistry 1959, 37, 1121. [CrossRef]

${ }^{50}$ Kurzer, F.; Canelle, J.Cyclization of 4substituted 1-amidinothiosemicarbazides to 1,2,4-triazole and 1,3,4-thiadiazole derivatives. Tetrahedron 1963, 19, 1603. [CrossRef]

${ }^{51}$ Rao, V. R.; Srinivasan, V.R. 1,3,4oxa(thia)diazoles: Part V 2-amino-5-aryl-1,3,4thiadiazoles. Indian Journal of Chemistry 1970, 8, 509. [Link]

${ }^{52}$ Husain, M. I.; Kumar, A.; Srivastava, R. C. Synthesis of N-(2-naphthyloxycetyl) thiosemicarbazides and 2-arylamino-5-(2naphthyloxymethyl)-1,3,4-

thiaiazoles/oxadiazoles as oral hypoglycemic agents. Current Science 1986, 55, 644. [Link]

${ }^{53}$ Palaska, E.; Sahin, G.; Kelicen, P.; Durlu, N. T.; Altinok, G. Synthesis and anti-inflammatory activity of 1-acylthiosemicarbazides, 1,3,4oxadiazoles, 1,3,4-thiadiazoles and 1,2,4triazole-3-thiones. IL Farmaco 2002, 57, 101. [CrossRef]

${ }^{54}$ Kaur, H.; Baghel, U. S.; Chawla, A.; Dhawan, R. K. Synthesis and antimicrobial evaluation of thiadiazole derivatives. Der Pharma Chemica 2014, 6, 66. [Link]

${ }^{55}$ Chaitanya, G.; Jhansi, G.; Susmitha, B.; Naveen, P. V.; Chenchu Lakshmi, B. Synthesis and evaluation of 2-substituted thiadiazole Schiff bases. International Journal of Pharmacy 2014, 4, 123. [Link]

${ }^{56}$ Katiyar, A.; Metikurki, B.; Prafulla, S.; Kumar, S.; Kushwaha, S.; Schols, D.; Clercq, E.; Karki, S. Synthesis and pharmacological activity of imidazo[2,1-b] [1,3,4] thiadiazole derivatives. Acta Poloniae Pharmaceutica 2016, 73, 937. [PubMed]

${ }^{57}$ Schuttelkopf, A. W.; Gros, L.; Blair, D. E.; Frearson, J. A.; Aalten, D. M. F. Acetazolamidebased fungal chitinase inhibitors. Bioorganic \& 
Medicinal Chemistry 2010, 18, 8334. [CrossRef] [PubMed]

${ }^{58}$ Epishina, M. A.; Kulikov, A. S.; Ignat'ev, N. V.; Schulte, M.; Makhoova, N. N. Synthesis of 5 alkyl-2-amino-1,3,4-thiadiazoles and $\alpha, \omega$ bis(2-amino-1,3,4-thiadiazol-5-yl) alkanes in ionic liquids. Mendeleev Communications 2011, 21, 331. [CrossRef]

59 Yang, S.J.; Lee, S.H.; Kwak H.J.; Gong, Y.D. Regioselective synthesis of 2-aminosubstituted 1,3,4-oxadiazole and 1,3,4thiadiazole derivatives via reagent-based cyclization of thiosemicarbazide intermediate. The Journal of Organic Chemistry 2013, 78, 438. [CrossRef] [PubMed]

${ }^{60}$ Niu, P.; Kang, J., Tian, X., Song, L., Liu, H., Wu, J., Yu, W., Chang, J. Synthesis of 2-amino1,3,4-oxadiazoles and 2-amino-1,3,4thiadiazoles via sequential condensation and $\mathrm{I}_{2}$-mediated oxidative $\mathrm{C}-\mathrm{O} / \mathrm{C}-\mathrm{S}$ bond formation. The Journal of Organic Chemistry 2015, 80, 1018. [CrossRef] [PubMed]

${ }^{61}$ Noolvi, M. N.; Patel, H. M.; Kamboj, S.; Cameotra, S. S. Synthesis and antimicrobial evaluation of novel 1,3,4-thiadiazole derivatives of 2-(4-formyl-2methoxyphenoxy) acetic acid. Arabian Journal of Chemistry 2016, 9, S1283. [CrossRef]

62 Yuan, H.; Liu, Q.; Zhang, L.; Shihe, H.; Chen, T.; Li, H.; Chen, Y.; Xu, Y.; Lu, T. Discovery, optimization and biological evaluation for novel c-met kinase inhibitors. European Journal of Medicinal Chemistry 2018, 143, 491. [CrossRef] [PubMed]

63 Skagius, K. Potencial Chemotherapeutics. Acta Chemica Scandinavica 1960, 14, 1054. [CrossRef]

${ }^{64}$ Foroumadi, A.; Mirzaei, M.; Shafiee, A.Antituberculosis agents, I: Synthesis and antituberculosis activity of 2-aryl-1,3,4thiadiazole derivatives. Pharmazie 2001, 56, 610. [PubMed]

65 Li, Z.; Feng, X.; Zhao, Y. Microwave induced efficient synthesis of (un)substituted benzaldehyde (5-aryl-1,3,4-thiadiazol-2yl)hydrazones using silica-supported dichlorophosphate as a recoverable dehydrant. Journal of Heterocyclic Chemistry 2008, 45, 1489. [CrossRef]

${ }^{66}$ Feng, H.; Ying, X.; Peng, Y.; Van der Eycken, E. V.; Liu, C.; Zhao, S.; Song, G. FeCl 3 - promoted synthesis of 1,3,4-thiadiazoles under combined microwave and ultrasound irradiation in water. Monatshefte für Chemie 2013, 144, 681. [CrossRef]

67 Kariyappa, A. K.; Gurunanjappa, P. Design, synthesis and biological evaluation of 1,3,4oxadiazoles/thiadiazoles bearing pyrazole scaffoldas antimicrobial and antioxidant candidates. Current Chemistry Letters 2016, 5, 109. [CrossRef]

${ }^{68}$ Kaushik-Basu, N.; Çakir, G.; Guhamazumder, R.; Tatar, E.; Manvar, D.; Basu, A.; Patel, B.; Zia, J., Talele, T. Novel 4-thiazolidinones as nonnucleoside inhibitors of Hepatitis C Virus NS5B RNA-dependent RNA polymerase. Archiv der Pharmazie-Chemistry in Life Sciences 2015, 348, 10. [CrossRef]

${ }^{69}$ Chen, H.; Li, Z.; Han, Y. Synthesis and fungicidal activity against Rhizoctonia solani of 2-alkyl (alkylthio)-5-pyrazolyl-1,3,4oxadiazoles (Thiadiazoles). Journal of Agricutural and Food Chemistry 2000, 48, 5312. [CrossRef] [PubMed]

${ }^{70}$ Kaur, H.; Kumar, S.; Vishwakarma, P.; Sharma, M.; Saxena, K. K.; Kumar, A. Synthesis and antipsychotic and anticonvulsant activity of some new substituted oxa / thiadiazolylazetidinonyl

thiazolidinonylcarbazoles. European Journal of Medicinal Chemistry 2010, 45, 2777. [CrossRef] [PubMed]

${ }^{71}$ Aggarwal, N.; Kumar, R.; Dureja, P.; Khurana, J. M. Synthesis of novel nalidixic acid-based 1,3,4-thiadiazole and 1,3,4oxadiazole derivatives as potent antibacterial agents. Chemical Biology \& Drug Design 2012, 79, 384. [CrossRef] [PubMed]

72 Padmavathi, V.; Reddy, G. S.; Padmaja, A.; Kondaiah, P.; Ali-Shazia. Synthesis, antimicrobial and cytotoxic activities of 1,3,4oxadiazoles, 1,3,4-thiadiazoles and 1,2,4triazoles. European Journal of Medicinal 
Chemistry 2009, 44, 2106. [CrossRef] [PubMed]

${ }^{73}$ Padmavathi, V.; Reddy, S. N.; Reddy, G. D.; Padmaja, A. Synthesis and bioassay of aminosulfonyl-1,3,4-oxadiazoles and their interconversion to 1,3,4-thiadiazoles. European Journal of Medicinal Chemistry 2010, 45, 4246. [CrossRef] [PubMed]

${ }^{74}$ Padmavathi, V.; Reddy, G. D.; Reddy, S. N.; Mahesh, K. Synthesis and biological activity of 2-(bis((1,3,4-oxadiazolyl/1,3,4-thiadiazolyl) methylthio)methylene)malononitriles.

European Journal of Medicinal Chemistry 2011, 46, 1367. [CrossRef][PubMed]

${ }^{75}$ Abdelhamid, A. O.; El Sayed, I. E.; Hussein, M. Z; Mangoud, M. M.Synthesis and antimicrobial activity of some new 1,3,4thiadiazoles and 3-(furan-2-yl)-5-(3-(furan-2yl)-4,5-dihydro-1-phenyl-1h-pyrazol-4-yl)-4,5dihydropyrazole-1-carbothioamide. World Journal of Pharmacy and Pharmaceutical Sciences 2016, 5, 1654. CCrossRef]

${ }^{76}$ Kaur, A.; Kaushal, M. A review on some 2,5disubstituted $[1,3,4]$ thiadiazole substituted thiazolidinone derivatives as a potent antimicrobial agents. World Journal of Pharmaceutical Research 2016, 5, 1966. [Link]

${ }_{77}$ Tahtaci, H.; Karacik, H.; Ece, A.; Er, M.; Gül Seker, M. Design, synthesis, SAR and molecular modeling studies of novel imidazo $[2,1-b][1,3,4]$ thiadiazole derivatives as highly potent antimicrobial agents. Molecular Informatics 2017, 36, 1. [CrossRef]

${ }^{78}$ Khalaj, A.; Nakhjiri, M.; Negahbani, A. S.; Samadizadeh, M.; Firoozpour, L.; Rajabalian, S. Samadi, N.; Faramarzi, M. A.; Adibpour, N.; Shafiee, A.; Foroumadi, A. Discovery of a novel nitroimidazolyleoxazolidinone hybrid with potent anti Gram-positive activity: Synthesis and antibacterial evaluation. European Journal of Medicinal Chemistry 2011, 46, 65. [CrossRef] [PubMed]

${ }^{79}$ Barbuceanu, S.F.; Saramet, G.; Almajan, G.L.; Draghici, C. New heterocyclic compounds from 1,2,4-triazole and 1,3,4-thiadiazole class bearing diphenylsulfone moieties. Synthesis, characterization and antimicrobial activity evaluation. European Journal of Medicinal Chemistry 2012, 49, 417. [CrossRef] [PubMed]

${ }^{80}$ Chandrakantha, B.; Isloor, A. M.; Shetty, P.; Fun, H. K.; Hegde, G. Synthesis and biological evaluation of novel substituted 1,3,4thiadiazole and 2,6-di aryl substituted imidazo [2,1-b] [1,3,4] thiadiazole derivatives. European Journal of Medicinal Chemistry 2014, 71, 316. [CrossRef] [PubMed]

${ }^{81}$ Seelam, N.; Prasanthi, S.; Shrivastava, S. P. Synthesis and anti-mycobacterial studies of some novel 1,3,4-thiadiazoles. Der Pharmacia Lettre 2016, 8, 1. [Link]

82 Radwan, A. A.; Alanazi, F. K.; Al-Agamy, M. H. 1,3,4-Thiadiazole and 1,2,4-triazole-3(4H)thione bearing salicylate moiety: synthesis and evaluation as anti-Candida albicans. Brazilian Journal of Pharmaceutical Sciences 2017, 53, 1. [CrossRef]

${ }^{83}$ Gür, M.; Sener, N.; Kastas, C. A.; Özkan, O. E.; Muglu, H.; Elmaswaria, M. A. M. Synthesis and characterization of some new heteroaromatic compounds having chirality adjacent to a 1,3,4-thiadiazole moiety and their antimicrobial activities. Journal of Heterocyclic Chemistry 2017, 54, 3578. [CrossRef]

${ }^{84}$ Xie, X.; Cong, W.; Zhao, F.; Li, H.; Xin, W.; Hou, G.; Wang, C. Synthesis, physiochemical property and antimicrobial activity of novel quaternary ammonium salts. Journal of Enzyme Inhibition Medicinal Chemistry 2017, 33, 98. [CrossRef] [PubMed]

${ }^{85}$ Padmaja, A.; Sekhara, M. M.; Nagarjuna, U.; Padmavathi, V.; Reddy, N. V.; Vijaya, T. Synthesis and antimicrobial activity of pyrimidinyl 1,3,4-oxadiazoles, 1,3,4thiadiazoles and 1,2,4-triazoles. European Journal of Medicinal Chemistry 2018, 145, 1. [PubMed] 